\title{
The influence of wave parameter definition over floating wind platform mooring systems under severe sea states
}

\author{
Carlos Barrera ${ }^{\mathrm{a}}$, Iñigo J. Losada ${ }^{\mathrm{a}}$, Raúl Guanche ${ }^{\mathrm{a}, *}$, Lars Johanning ${ }^{\mathrm{b}}$

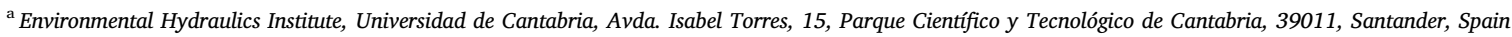 \\ ${ }^{\mathrm{b}}$ Renewable Energy Research Group, University of Exeter, Penryn Campus, Cornwall, UK
}

\section{A R T I C L E I N F O}

\section{Keywords:}

Mooring system

Spectrum

Wave groupiness

Extreme loads

Quasi-static model

Dynamic model

\begin{abstract}
A B S T R A C T
This paper explores the role of wave spectral characteristics and wave time history on the estimation of extreme mooring loads on floating offshore wind turbines. This research is applied to the DeepCwind semi-submersible platform located at the BiMEP test site in the North of Spain. Extreme sea states are selected using the inverse first-order reliability method (I-FORM). Mooring loads are modelled by quasi-static and dynamic numerical approaches. Different wave time series are generated numerically for each sea state to investigate the variability in predicted peak loads. All cases simulated incorporate the combined effect of wind and waves. Differences of approximately $30 \%$ in peak loads are found for the mooring system, reaching $40-79 \%$ for the most extreme sea states. Safety factors are proposed to account for sensitivity to wave groupiness in modelling loads under extreme work conditions of the DeepCwind platform (e.g., pitch and velocity control). A comparison between theoretical and real-sea wave spectra is also modelled to investigate possible differences due to the presence of multiple spectral peaks associated with swell and wind seas. In general, results show differences below $12 \%$ in the prediction of loads between both assumptions.
\end{abstract}

\section{Introduction}

Offshore wind energy is one of the most prominent, competitive and reliable sources for power generation. Traditionally, wind turbines are installed on fixed foundations such as gravity-based structures, monopiles, jackets or tripods. However, the cost-effectiveness ratio of fixed foundations in deep waters is not competitive and the continuous technological development have contributed to the emergence of new alternatives. The most immediate option is installing wind turbines on floating platforms. Different floating offshore wind turbine (FOWT) concepts have been developed, such as the spar buoy, the semi-submersible and the tension leg platform. Each has specific technical challenges and a unique dynamic response. Despite conceptual differences among them, all concepts require a mooring system to ensure their survival and station keeping in the harsh marine environment and to achieve a successful platform design. Mooring systems are an important element to the stability of FOWTs. Currently, several possible mooring configurations and types of components are available (Harris et al., 2004): spread moorings (catenary, multi-catenary with weights and buoys and taut spread mooring); single point mooring (turret mooring, catenary anchor leg mooring (CALM) and single anchor leg mooring (SALM)); and dynamic positioning (active mooring and propulsion).

Numerical modelling techniques are commonly applied to estimate the performance of these systems on a floating platform. Traditionally, tensions at the fairlead can be evaluated by quasi-static or dynamic models. Quasi-static models have a low computational cost but do not evaluate drag and inertial forces considered in dynamic models. Mooring models have been widely studied through simulations and laboratory tests (Barrera et al, 2019; Barrera et al., 2017; Azcona et al., 2017a; Lindahl, 1985). Models coupling hydrodynamics, aerodynamics and mooring systems are especially relevant when estimating the response of offshore floating platforms. Numerous studies have been carried out to address possible uncertainties that these models may induce. Specifications used for numerical modelling are described in the Offshore Code Comparison Collaboration Continuation with Correlation (OC5 Project) (Robertson et al. , 2014b; Robertson et al, 2017). The effects of the different approaches on hydrodynamic models were demonstrated in (Hall and Goupee, 2015), in which approaches with full second-order wave forces and viscous mean drift forces were compared with laboratory tests.

Traditionally, the design of mooring lines for floating structures is

\footnotetext{
* Corresponding author.

E-mail address: guancher@unican.es (R. Guanche).
} 
based on considering several limit states (DNVGL-OS-E301, 2015; Haukanes et al., 2017): ultimate (ULS), accidental (ALS), fatigue (FLS) and service (SLS). The ULS and FLS contribute to determining the mooring line resistance required to withstand extreme environmental loads and the accumulated load cycles over a given lifetime of a structure. The ALS refers to events of accidental damage and evaluates the resistance of a mooring system after damage has occurred. The SLS represents the requirement that structure be able to meet its service criteria. The verification of each limit state requires the identification of the metocean conditions and their variability at a particular location to estimate the profitability of a project. Different techniques, including algorithms based on clustering and selection (Camus et al., 2011) and environmental contour lines methods (Haver and Winterstein, 2008; Del Jesus et al., 2015; DNV-RP-C205, 2014), have been developed to evaluate the long-term effects of metocean conditions.

This article focuses on the design of extreme loads (ULS) on the mooring lines of a FOWT, building on prior research on this topic. The evaluation of the mooring loads according to IEC 61400-3 (IEC 614003) was reported in (Azcona et al., 2017b), and different formulations have been proposed to characterise the extreme mooring tensions due to snap loads (Hsu et al., 2017). Additionally, the effects of environmental conditions on peak mooring loads were evaluated for marine energy converters through field tests in (Harnois et al., 2016). Previous studies have not clearly demonstrated the influence of wave time history or real-sea wave spectra in the evaluation of extreme loads as key factors for a safe mooring design.

The innovation of this study is the evaluation of the impact of different wave characterisation (spectrum and time series) on mooring design load. Wave definitions can be described in the time domain or frequency domain. A particular sea state can be defined by multiple free surface temporal series each one with a different wave groupiness distribution in the time domain. Wave groupiness is a sequence of wave trains characterised by a height, period and energy taking part of a sea state. The adding of all wave groupiness constitutes the complete sea state time series. This study analyses the design load through two statistical techniques: the selection of peak loads and the maximum local. Additionally, safety factors are proposed to quantify the uncertainty associated with wave history. From the frequency domain point of view, the wave description is achieved by means of a theoretical spectrum such as a JONSWAP or Pierson-Moskowitz. However, this assumption can generate wave energy distribution uncertainties in comparison with real-sea wave spectra in the target location. Theoretical spectra concentrate wave energy around one peak, but the wave energy may be distributed over multiple peaks. The different wave energy distribution in the spectrum is evaluated comparing theoretical and buoy measurements to estimate the variability of peak loads on mooring system.

A methodology involving numerical models of mooring systems is implemented to evaluate the variability of peak loads as a consequence of different wave definitions. Loads on a mooring system are analysed according to two different sources of uncertainty associated with waves: 1) wave time history characterised by the presence of different wave groupiness and 2) wave spectrum shape. The remainder of the paper is organised as follows. In section 2, the methodology used in this work, the location examined, metocean databases and buoys, the definition of FOWT and the numerical models studied are described. Section 3 describes the sea states selected and the numerical results obtained from the calibration and validation, as well as the analysis of loads on the mooring systems. The main conclusions of this investigation are presented in section 4 .

\section{Methodology}

This section describes the method developed to evaluate loads on a mooring system considering (i) site conditions, (ii) sea states, (iii) platform design criteria, (iv) numerical model approach, and (v) peak load assessment of the mooring system. A schematic description of the methodology is provided in Fig. 1.

The study considers a particular location and a specific type of floating platform using three different steps. The objective of the first step is to analyse the design sea states of the proposed installation location using metocean data. The second step involves the implementation and validation of the numerical model developed to simulate FOWT behaviour in terms of movements and tensions relative to laboratory tests. Finally, the third step uses the validated numerical model to estimate the peak mooring loads for specific sea states selected in the first step.

\subsection{Site assessment}

The location selected for this study is BiMEP test site $\left(-2.894^{\circ}\right.$, $43.563^{\circ}$ ), an area off Armintza in the Basque Coast (North of Spain). This location is characterised by a predominant regime of waves coming from the north-west direction with an average significant wave height of $1.7 \mathrm{~m}$, maximum values of approximately $9 \mathrm{~m}$, and periods between 8 and 12s, (Fig. 2) (Metocean Analysis of BiMEP, 2017; Iturrioz et al., 2017). The average wind speed is $7 \mathrm{~m} / \mathrm{s}$, and winds generally come from the west, south and east, with the strongest winds blowing westward at a velocity of over $20 \mathrm{~m} / \mathrm{s}$. Regime of winds is presented in Fig. 2 at $10 \mathrm{~m}$ over the surface.

\subsection{Sea states}

Sea states are defined by combining metocean hindcast and instrumental data using statistical techniques. Two different sea state selection methods are considered in this research. The first one is based on the application of I-FORM described in (Haver and Winterstein, 2008; Del Jesus et al., 2015). Its main target is to predict the metoceanic characteristics for different return periods. The data used in this selection comprise the reanalysis database described in section 2.2.1. The objective of this first selection method is to study the variability of the loads of the mooring lines based on a theoretical spectrum (JONSWAP) using random seedings on the wave time series reconstruction to obtain different distributions of wave groupiness. The goal of the second selection method is to analyse the variability of the loads on the mooring lines by comparing the theoretical and observed spectra. Observations are described in detail in section 2.2.2. The results of the selection methods are presented in sections 3.1.1 and 3.1.2.

\subsubsection{Numerical metocean data}

Wind and wave resource assessment at global, regional and local scales requires the use of numerical databases due to the coarse spatial resolution of instrumental measurements. Numerical databases provide long time series that allow for the characterisation of wind and wave performance in the long-term. Information used in this work is derived from the reanalysis databases developed by IHCantabria and BiMEP in the framework of TRL + project (Metocean Analysis of BiMEP, 2017).

The methodology used to generate the wind numerical database Seawind is described in (Menendez et al., 2014). Undisturbed mean wind speeds and directions for the 1985-2015 period are provided with a resolution of $1 \mathrm{~h}$. Wind data are modelled with the Weather Research \& Forecasting model and the module Advanced Research dynamical solver, developed by the National Center for Atmospheric Research (Skamarock et al., 2008). This limited area model (LAM) is coupled to the global atmospheric Climate Forecast System Reanalysis (Saha et al., 2010), which provides the boundary and initial conditions. Regarding sea state parameters, the Simulating Waves Nearshore model (Ris et al., 1999) is used to generate the Global Ocean Waves (GOW) database (Reguero et al., 2012). Significant wave heights, wave peak periods and prevailing wave directions for the 1985-2015 period are provided with a $1 \mathrm{~h}$ resolution.

Metocean hindcast is used to assess long-term environmental 


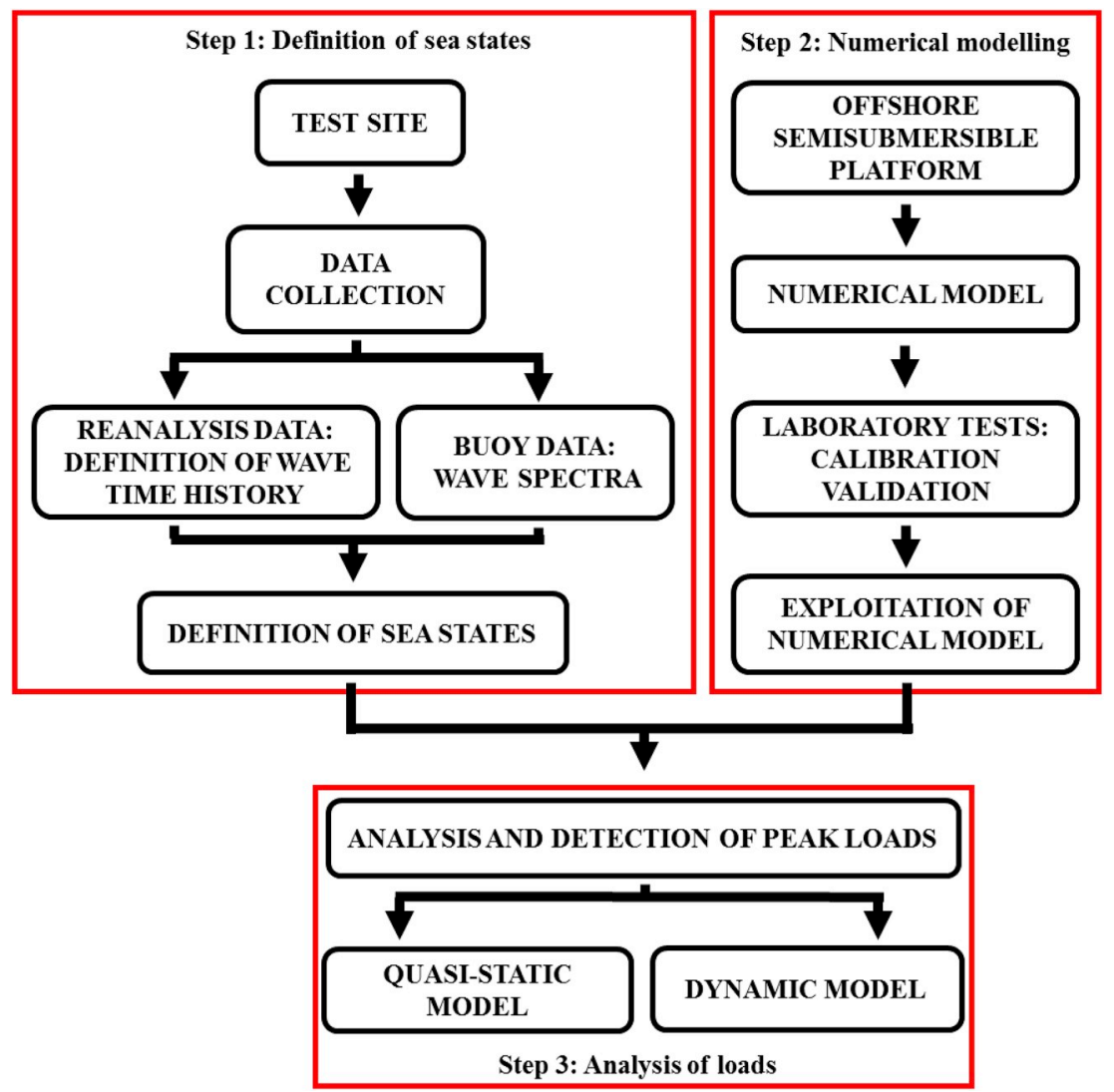

Fig. 1. Methodology of work.
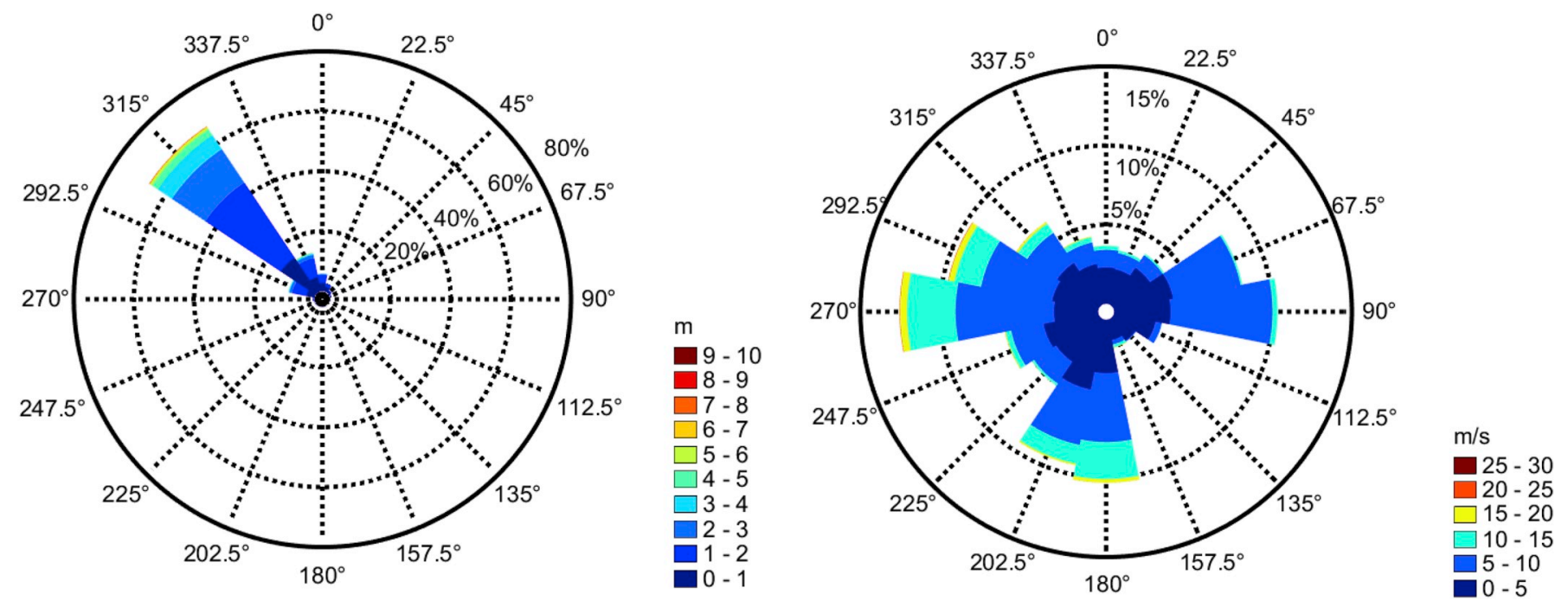

Fig. 2. Regime of waves (left rose) and winds (right rose) in Armintza.

conditions in a specific location. Marine structures design standards recommend using environmental conditions for a given annual exceedance probability. For this reason, different methods have been proposed over the years for the selection of a representative subset of a large amount of data. In this paper, the inverse first-order reliability method (I-FORM) is applied (Haver and Winterstein, 2008; Del Jesus et al., 2015). This method proposes to obtain the long-term metocean conditions generating an environmental contour corresponding to a certain return period given by standards (DNV-RP-C205, 2014).

\subsubsection{Measured metocean data}

Two different sources of observations are used in this work: 1) the BiMEP-WAVESCAN buoy and 2) the ANTEIA buoy.

The WAVESCAN directional buoy installed at the BIMEP (Metocean Analysis of BiMEP, 2017; Iturrioz et al., 2017) test site is located two nautical miles off the Basque coast $\left(-2.8848^{\circ} \mathrm{E}, 43.4682^{\circ} \mathrm{N}, 80 \mathrm{~m}\right.$ depth). The collected metocean data (currents, wind and waves) are stored internally in the data logger, and only a limited number of parameters are transmitted to the shore station in real time using 


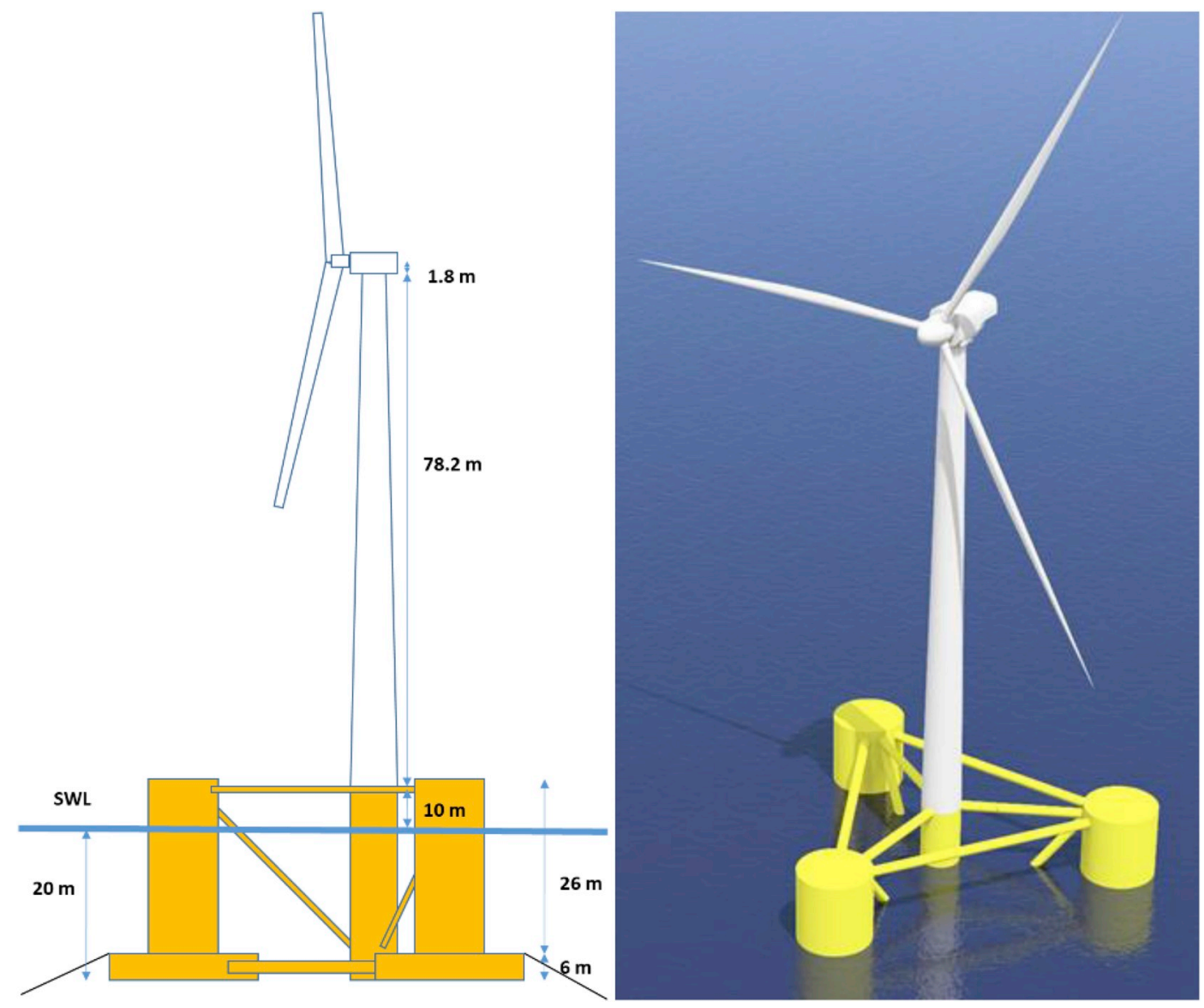

Fig. 3. DeepCwind semisubmersible platform.

satellite communication. Only one set of statistical data are available from this buoy, specifically, mean wind speed, significant wave height and wave peak period. Wind characteristics provided by this buoy are used in this research.

The ANTEIA is a directional wave buoy located at BIMEP with a diameter of $0.6 \mathrm{~m}$ and a weight of $26 \mathrm{~kg}$. This oceanographic buoy allows for the collection of wave height, direction, period data, as well as water temperature, in real time. Statistical and spectral parameters are provided by the buoy every $1800 \mathrm{~s}$. Wave spectral data provided by this buoy are employed in this research.

\subsection{Definition of offshore semisubmersible platform: DeepCwind semisubmersible}

The FOWT under investigation was the DeepCwind semisubmersible platform (Robertson et al,) (Fig. 3). The platform has three columns with heave plates and a fourth central column where a $5 \mathrm{MW}$ wind turbine (Jonkman et al., 2009) from the National Renewable Energy

Table 1

FOWT parameters.

\begin{tabular}{ll}
\hline FLOATING STRUCTURE & \\
\hline Mass & $1.3958 \mathrm{E}+7 \mathrm{~kg}$ \\
Draft & $20 \mathrm{~m}$ \\
Displacement & $1.3917 \mathrm{E}+4 \mathrm{~m}^{3}$ \\
CM location below SWL & $8.07 \mathrm{~m}$ \\
Roll inertia about CM & $1.3947 \mathrm{E}+10 \mathrm{~kg}-\mathrm{m}^{2}$ \\
Pitch inertia about CM & $1.5552 \mathrm{E}+10 \mathrm{~kg}-\mathrm{m}^{2}$ \\
Yaw inertia about CM & $1.3692 \mathrm{E}+10 \mathrm{~kg}-\mathrm{m}^{2}$ \\
\hline
\end{tabular}

Table 2

Mooring system parameters.

\begin{tabular}{ll}
\hline MOORING SYSTEM & \\
\hline Number of mooring lines & 3 \\
Angle between mooring lines & $120^{\circ}$ \\
Depth to anchors below SWL & $200 \mathrm{~m}$ \\
Depth to fairleads below SWL & $14 \mathrm{~m}$ \\
Equivalent diameter of mooring lines & $0.1393 \mathrm{~m}$ \\
Mass Density of mooring lines & $125.6 \mathrm{~kg} / \mathrm{m}$ \\
Stiffness of mooring lines & $7.461 \mathrm{E}+6 \mathrm{~N}$ \\
Mooring line length & $835.5 \mathrm{~m}$ \\
\hline
\end{tabular}

Laboratory (NREL) is mounted. Station keeping is provided by three catenary chain moorings. This platform has been widely studied by laboratory tests and simulations (Robertson et al, 2014; Hall and Goupee, 2015; Robertson et al, 2017). The most important features of this platform and its mooring system with respect to sea water level (SWL) and centre of mass (CM) are shown in Table 1 and Table 2, respectively. The coordinate system (Fig. 4) used in this investigation is set such that waves and wind travel from the negative to positive $\mathrm{x}$-axis. This direction is set to represent zero degrees. All simulations in this work are referred to this direction.

\subsection{Description of the numerical model}

A complete numerical model in the time domain has been implemented with the purpose of modelling the dynamic behaviour of FOWT (Martini et al., 2015; Armesto et al., 2016; Armesto et al., 2017). This section presents the main characteristics of the model describing the governing equation and other relevant considerations related to it. 


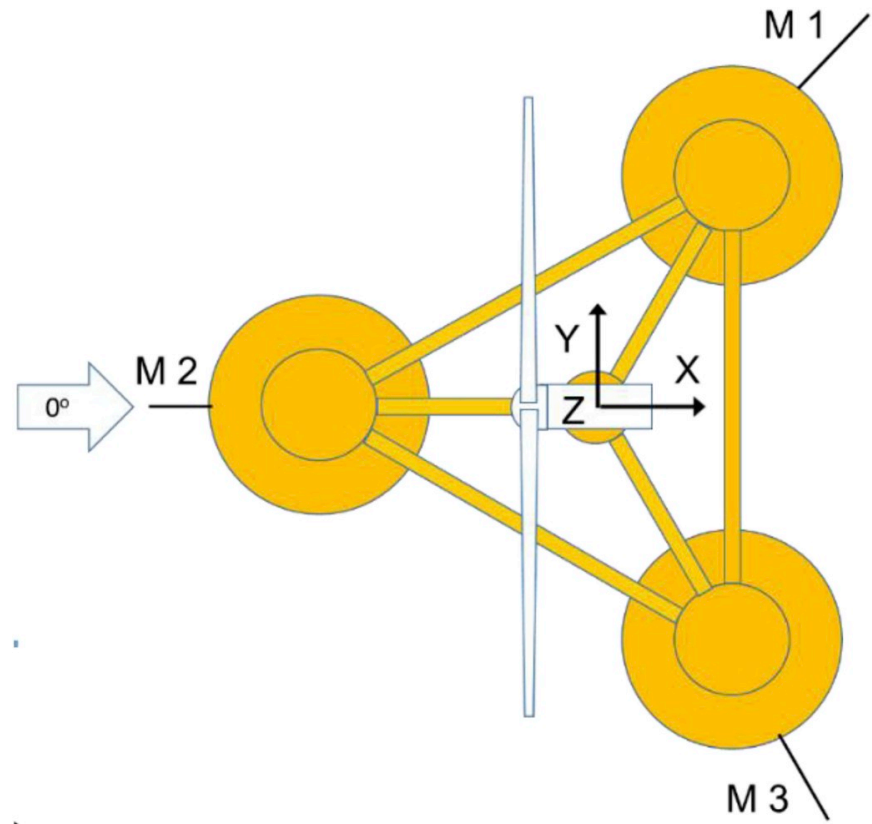

Fig. 4. Coordinate system and reference of the different mooring lines (M1, M2, M3).

The numerical model is built by coupling three different models corresponding to the hydrodynamic, aerodynamic and mooring systems. Each model solves the governing equations from each system individually. The hydrodynamic model is focused on describing the global response (movements and rotations) of the platform. The mooring model analyses the evolution of the forces on the mooring lines that are applied over the floating platform. The aerodynamic model examines the velocity of rotation of the wind turbine, which provides forces and momenta over the floating platform. The three models are coupled and solved under a unique system of equations providing information at each time step.

The hydrodynamic model solves the Cummins' equation (Cummins, 1962), a second-order ordinary differential equation with a convolution integral applied to solve the radiation problem (1).

$\left(M+A_{\infty}\right) \ddot{k}(t)+\int_{0}^{\infty} K(t-\tau) \dot{k}(\tau) d \tau+G k(t)=F_{e}(t)+F_{c}(t)+F_{w}(t)+F_{m}(t)$

where $M$ is the corresponding inertia matrix of the floating structure, $A_{\infty}$ is the added mass matrix at infinite frequency, $K$ is the retardation matrix, $G$ is the hydrostatic stiffness matrix, t is time and $\ddot{k}, \dot{k}$, and $k$ are the floating platform acceleration, velocity and displacements, respectively. External forces are represented by wave excitation forces $\left(F_{e}\right)$, current forces $\left(F_{c}\right)$, wind forces $\left(F_{w}\right)$ and mooring system forces $\left(F_{m}\right)$.

Traditionally, the majority of hydrodynamic codes use only firstorder theory for potential flow; therefore, the codes only consider forces and movements at the same frequency as that of the incident wave. The first-order theory neglects the nonlinearity in the incident wave potential of steeper waves. The first-order velocity potential is obtained by a superposition of the hydrostatic, radiation and diffraction problems in the floating structure mean position. This solution is adequate for small wave amplitudes as well as small platform motions. The available alternatives to take into account the nonlinearity range from the higherorder boundary element methods to cutting-edge Navier Stokes equations. The second-order hydrodynamic theory (Pinkster, 1980;Simos et al., 2018) attempts to approximate the nonlinear free surface boundary condition and wave body interactions using the superposition of the quadratic interaction of the first-order velocity terms as well as terms of the second-order solution of the velocity potential. The model presented herein neglects the contribution of the second-order potential in the numerical computation of the force term (Simos et al., 2018).

For irregular waves with $\mathrm{N}$ components and $\mathrm{j}$ degrees of freedom, the first-order wave excitation force can be represented by (2).

$F_{e(1), j}=\operatorname{Re}\left(\sum_{n=1}^{N} A_{n} Q_{j}\left(w_{n}\right) e^{i\left(w_{n} t\right)}\right), \quad j=1,2,3,4,5,6$

where $A_{n} e^{i\left(w_{n} t\right)}$ is the complex wave component, $A_{n}$ is the complex wave amplitude, $w_{n}$ is the wave frequency, $i$ is the imaginary number and $Q_{j}\left(w_{n}\right)$ represents the first-order complex excitation transfer function associated with $w_{n}$ and j. $A_{n}$ can be written as $A_{n}=a_{n} e^{i \varepsilon_{n}}$, where $a_{n}$ is the wave amplitude and $\varepsilon_{n}$ the wave phase, and $Q_{j}\left(w_{n}\right)$ is $Q_{j}\left(w_{n}\right)=q_{n}\left(w_{n}\right) e^{i \varphi_{n j}}$, where $q_{n}$ is the amplitude of the first-order force per wave amplitude unit and $\varphi_{n j}$ its phase.

The second-order wave excitation (Pinkster, 1980; Gueydon et al., 2014; Duarte et al., 2014;Simos et al., 2018) is defined by the contributions of the sum and difference frequencies between pairs of waves using the double Fourier transform (3). Therefore, for each pair with amplitudes $A_{n}$ and $A_{m}$ and frequencies $w_{n}$ and $w_{m}$, two different quadratic transfer functions (QTFs), $Q_{j}^{+}\left(w_{n} w_{m}\right)$ and $Q_{j}^{-}\left(w_{n} w_{m}\right)$, can be obtained.

$F_{e(2), j}=\operatorname{Re}\left(\sum_{n=1}^{N} \sum_{m=1}^{N}\left[A_{n} A_{m} Q_{j}^{+}\left(w_{n} w_{m}\right) e^{i\left(w_{n}+w_{m}\right) t}+A_{n} A_{m}^{*} Q_{j}^{-}\left(w_{n} w_{m}\right) e^{i\left(w_{n}+w_{m}\right) t}\right]\right)$

where $(*)$ denotes the complex conjugate.

According to (Gueydon et al., 2014), the sum frequency secondorder loads can be neglected in spread moored semisubmersible platforms because the sum frequency loads can exceed the wave frequency. Following (Pinkster, 1980; Duarte et al., 2014), the difference frequency term can separate the double summation into three regions: $\mathrm{m}=\mathrm{n}, \mathrm{m}>\mathrm{n}$, and $\mathrm{m}<\mathrm{n}$. However, these three regions can be written as two terms due to the symmetry of $m>n$ and $m<n$. Hence, the second-order wave excitation force can be represented as follows (4).

$$
\begin{aligned}
F_{e\left(2^{-}\right), j}= & R e\left(\sum_{n=1}^{N} A_{n} A_{n}^{*} Q_{j}^{-}\left(w_{n}, w_{n}\right)\right. \\
& \left.+2 \sum_{n=1}^{N} \sum_{m=n+1}^{N} A_{n} A_{m}^{*} Q_{j}^{-}\left(w_{n}, w_{m}\right) e^{i\left(w_{n}-w_{m}\right) t}\right)
\end{aligned}
$$

The first term represents the mean drift loads and the second the slow drift loads. The mean drift loads generate a mean offset, while the slow drift loads can excite resonant movements in the low-frequency range of the floating structure. The transfer functions as well as the hydrodynamic matrices are calculated by ANSYS AQWA (ANSYS $A Q W A, 2013)$, and transfer into the time domain is performed using an in-house numerical code. The QTFs of the difference for the zero degree direction are represented in Fig. 5. It should be noted that the highest difference between QTFs is found in the pitch motion (Gueydon et al., 2014).

The aerodynamic model used (De los Dolores et al., 2017) is based on blade element momentum (BEM) theory. Each blade is discretised into separate elements with different physical and aerodynamic properties. The relative velocity of each element is calculated at each time step. The angle of attack can then be obtained, providing the lift and drag coefficients over the element and the normal and tangential components of the force. The model does not take into account aeroelasticity and its possible effects. The rotor torque $\left(T_{R}\right)$ and forces and momenta of the wind turbine over the floating platform are obtained by integrating the forces computed at each element of the blades. A control system, variable in pitch and velocity, is implemented as part of the 

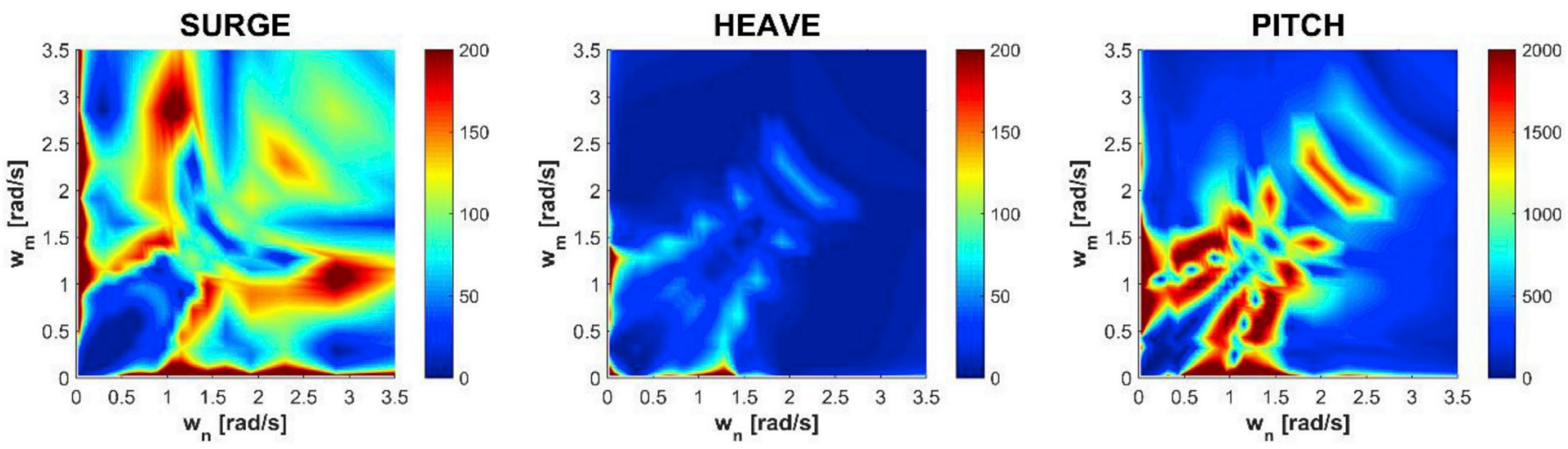

Fig. 5. Quadratic transfer functions $\left[\mathrm{kN} / \mathrm{m}^{2}\right]$.

BEM model, which provides the generator torque $\left(\mathrm{T}_{\mathrm{G}}\right)$ and the pitch of each blade. The variation of the velocity of rotation of the blades $(\Omega)$ is given as a function of the inertia of the wind turbine $\left(\mathrm{I}_{\mathrm{WT}}\right)$, the rotor torque $\left(\mathrm{T}_{\mathrm{R}}\right)$ and the generator torque $\left(\mathrm{T}_{\mathrm{G}}\right)$ as follows:

$I_{W T} \dot{\Omega}(t)=T_{R}(t)-T_{G}(t)$

Two different approaches to obtain the behaviour of the catenary in terms of tensions and movements are built into the mooring model: a quasi-static model and a dynamic model. The quasi-static approach assumes that the line is in static equilibrium at each time step neglecting the inertia, current and wave forces on the line. The main advantage of this approach is its numerical efficiency. The analytical equations of the mooring lines (Jonkman and Buhl, 2007) with seabed interactions are given in (6). These equations are described in 2D for a vertical plane including an anchor and fairlead.

$x_{s}=\left\{\begin{array}{c}s, 0 \leq s \leq L_{B}-\frac{H_{F}}{C_{B \rho_{0}}} \\ s+\frac{C_{B} \rho_{0}}{2 E A}\left[s^{2}-2\left(L_{B}-\frac{H_{F}}{C_{B \rho_{0}}}\right) s+\left(L_{B}-\frac{H_{F}}{C_{B \rho_{0}}}\right) M A X\left(L_{B}-\frac{H_{F}}{C_{B \rho_{0}}}, 0\right)\right], \\ L_{B}-\frac{H_{F}}{C_{B} \rho_{0}} \leq s \leq L_{B} \\ L_{B}+\frac{H_{F}}{\rho_{0}} \ln \left[\frac{\rho_{0}\left(s-L_{B}\right)}{H_{F}}+\sqrt{1+\left(\frac{\rho_{0}\left(s-L_{B}\right)}{H_{F}}\right)^{2}}\right]+\frac{H_{F} s}{E A} \\ +\frac{C_{B \rho_{0}}}{2 E A}\left[-L_{B}^{2}+\left(L_{B}-\frac{H_{F}}{C_{B} \rho_{0}}\right) M A X\left(L_{B}-\frac{H_{F}}{C_{B} \rho_{0}}, 0\right)\right], L_{B} \leq s \leq L\end{array}\right.$

$z_{s}=\left\{\begin{array}{c}0, \quad 0 \leq s \leq L_{B} \\ \frac{H_{F}}{\rho_{0}} \ln \left[\sqrt{1+\left(\frac{\rho_{0}\left(s-L_{B}\right)}{H_{F}}\right)^{2}}-1\right]+\frac{\rho_{0}\left(s-L_{B}\right)^{2}}{2 E A}, \quad L_{B} \leq s \leq L\end{array}\right.$

$T_{s}=\left\{\begin{array}{c}\operatorname{MAX}\left(H_{F}+C_{B} \rho_{0}\left(s-L_{B}\right), 0\right), \quad 0 \leq s \leq L_{B} \\ \sqrt{H_{F}^{2}+\left(\rho_{0}\left(s-L_{B}\right)\right)^{2}}, \quad L_{B} \leq s \leq L\end{array}\right.$

where $s$ denotes the longitudinal coordinate, $C_{B}$ the static friction coefficient, $\rho_{0}$ the linear weight, $E$ the Young's modulus, $A$ the sectional area, $L_{B}$ the unstretched length of a mooring line resting on the seabed, $L$ the total unstretched length of a mooring line, $H_{F}$ the horizontal component of the tension at the fairlead, $x_{s}$ the horizontal distance between the anchor and a point on a mooring line, $z_{s}$ the vertical distance between the anchor and a point on a mooring line and $T_{s}$ the tension at a point on a mooring line.

The dynamic approach (Aamo and Fossen, 2000) solves the mooring line as a flexible cable by means of a one-dimensional second-order non-linear wave equation. This equation is formulated using Newton's second law (7) and solved by a finite element method neglecting bending and torsion stiffness.

$\rho_{0} \frac{\partial^{2} \vec{r}}{\partial t^{2}}=\frac{\partial}{\partial s}\left(\frac{T_{s}}{1+e} \frac{\partial \vec{r}}{\partial s}\right)+\vec{f}(1+e)$ where $\vec{r}$ is the position vector, $e$ the deformation and $\vec{f}$ the sum of external forces acting on the cable.

The external forces $(\vec{f})$ are a sum of the buoyancy force $\left(\vec{f}_{h g}\right)$, the drag force, normal $\left(\vec{f}_{d n}\right)$ and tangential, $\left(\vec{f}_{d t}\right)$ components, the inertia force $\left(\vec{f}_{i}\right)$ and the seabed contact force in the normal $\left(\vec{f}_{s b, n}\right)$ and horizontal $\left(\vec{f}_{s b, t}\right)$ directions. Their formulations (Aamo and Fossen, 2000; Hall and Goupee, 2015) are given by the following equations:

$\vec{f}=\vec{f}_{h g}+\vec{f}_{d n}+\vec{f}_{d t}+\vec{f}_{i} \quad \vec{f}_{h g}=\rho_{0} \frac{\rho_{c}-\rho_{w}}{(1+e) \rho_{c}} \vec{g}$

$\overrightarrow{f_{d n}}=-\frac{1}{2} C_{D N} d \rho_{w}\left|\vec{v}_{n}\right| \vec{v}_{n} \quad \vec{f}_{d t}=-\frac{1}{2} C_{D T} d \rho_{w}\left|\vec{v}_{t}\right| \vec{v}_{t} \quad \overrightarrow{f_{i}}$

$=-C_{I} \frac{\pi d^{2}}{4} \rho_{w} \vec{a}_{n}$

$\vec{f}_{s b, n}=d\left[\left(z_{b o t}-r^{z}\right) K_{G}-\dot{r}^{z} K_{B}\right] r^{z} \vec{f}_{s b, t}=f_{h g} K_{\mu} \min \left(\frac{\dot{r}^{x y}}{v_{\mu}}, 1\right) \frac{\dot{r}^{x y}}{\dot{r}^{x y}}$

where $\vec{g}$ is gravitational acceleration, $\rho_{c}$ the cable density, and $\rho_{w}$ the density of water. $C_{D N}$ and $C_{D T}$ are normal and tangential drag coefficients; $d$ is the cable diameter; $C_{I}$ is a hydrodynamic mass coefficient; $\vec{v}$ and $\vec{a}$ are the velocity and acceleration denoted by the subscripts $\mathrm{n}$ and $\mathrm{t}$, the decompositions into the normal and tangential directions, respectively; $z_{b o t}$ is the vertical coordinate of the seabed; and $r^{z}$ is the vertical projection of the position vector and $\dot{r}^{z}$ its velocity. Constants $K_{G}$ and $K_{B}$ represent the stiffness and viscous coefficients, respectively. In the horizontal term, $K_{\mu}$ is the coefficient of kinetic friction corresponding to a maximum velocity $v_{\mu}$, and $\dot{r}^{x y}$ represents the velocity of the horizontal projection of the position vector.

\subsection{Detection of peak loads}

The methodology used to detect peak loads on mooring lines is described in (Harnois et al., 2016). The detection of peaks in a load time series is achieved by defining two parameters: $\tau$ and $\mathrm{K} . \tau$ is a threshold used to identify peak loads with sufficient amplitude, while $\mathrm{K}$ isolates all of them. The parameter $\tau$ is defined as a percentage (n) over the mean value of the load $(\overline{\mathrm{F}})$ and the parameter $\mathrm{K}$ is compared to the standard maximum score (S) that relates the dynamic part of the load $(\mathrm{F}-\overline{\mathrm{F}})$ to its dispersion $\left(\sigma_{\mathrm{F}}\right)$. The variable $\mathrm{k}$ defines the maximum force threshold using $\mathrm{K}$. The formulation of the standard maximum score is given by

$S_{\max }=\frac{\max (F)-\bar{F}}{\sigma_{F}}$ 


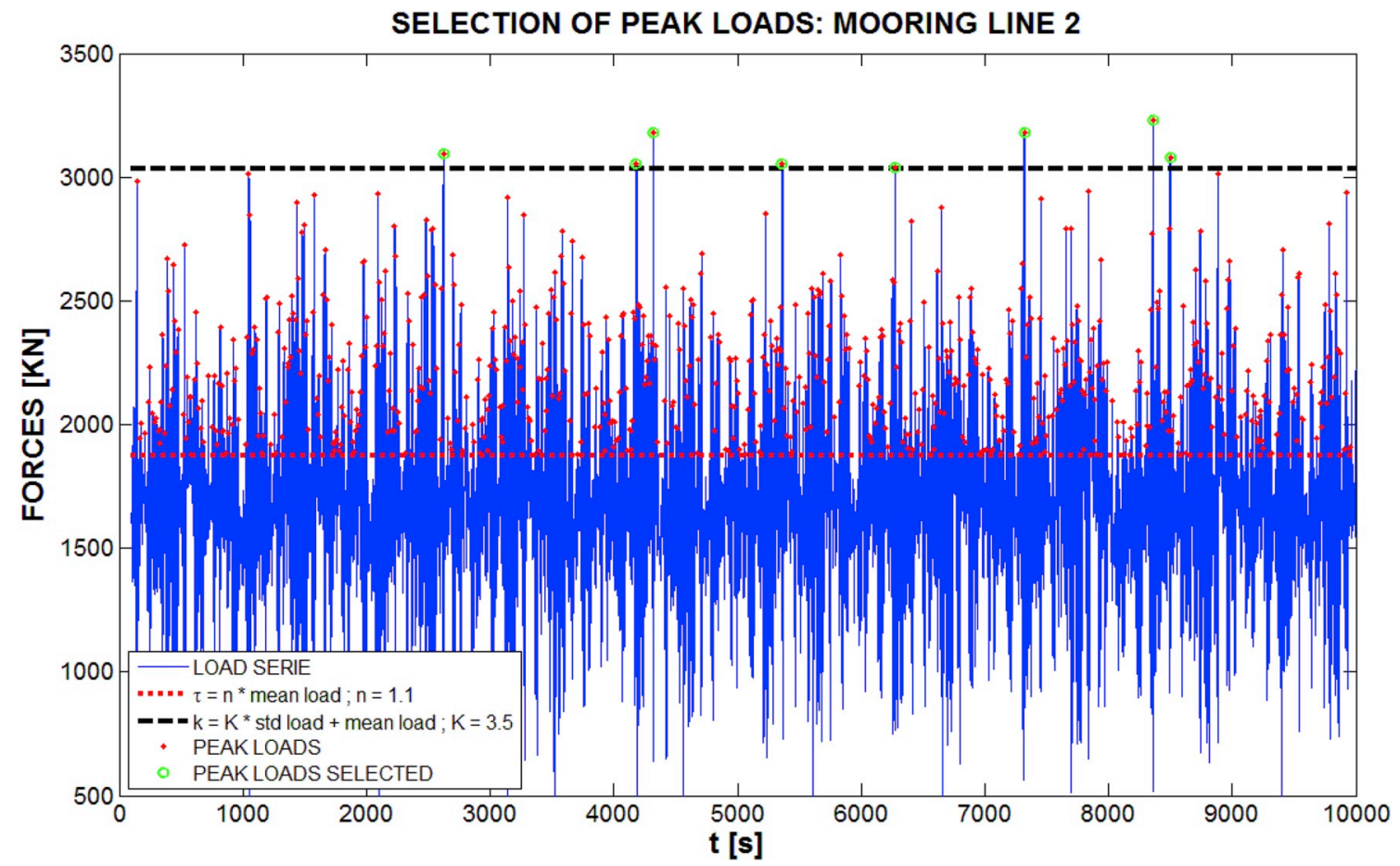

Fig. 6. Selection of peak loads: $\tau$ and K parameters.

The effect of these parameters on the selection of peak loads is shown in Fig. 6 and Fig. 8. In Fig. 6, a load time series is represented as a continuous line together with the load thresholds given by the parameters $\tau$ (dotted line) and $\mathrm{k}$ (dashed line). The peak loads in circles are chosen as a result of this selection. This figure reveals the importance of these parameters on the selection of peak loads. In addition, the parameters depend on the sea state considered and the number of mooring lines of the floating structure. For this reason, the parameters must be determined through a sensitivity analysis.

The mooring system of the DeepCwind semisubmersible platform has three mooring lines. A sensitivity analysis is carried out to determine the percentage of peak loads on the most and least loaded
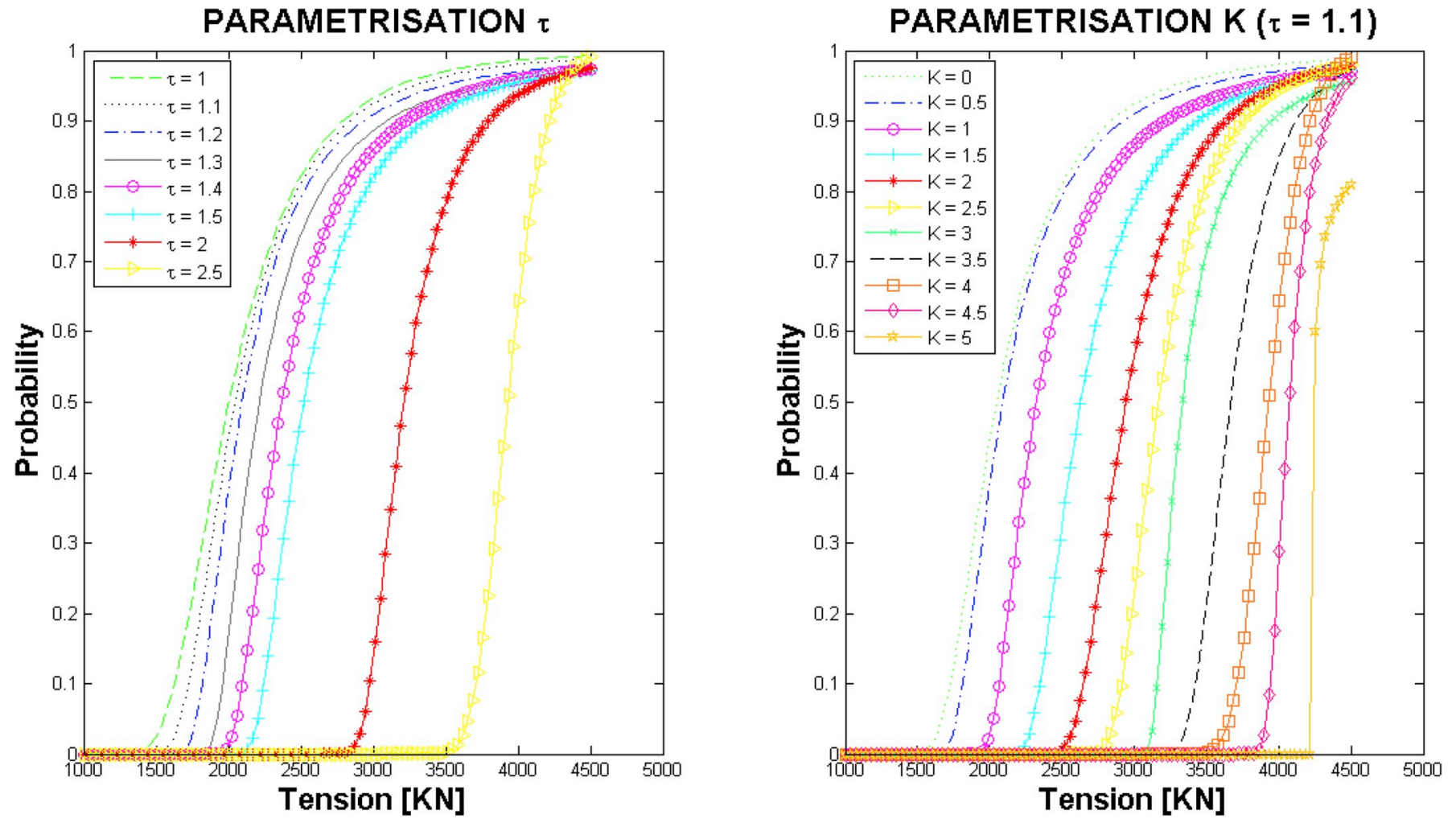

Fig. 7. Parametric analysis of $\tau$ and K parameters: load distribution functions. 
LOAD PEAKS ON THE MOORING LINE

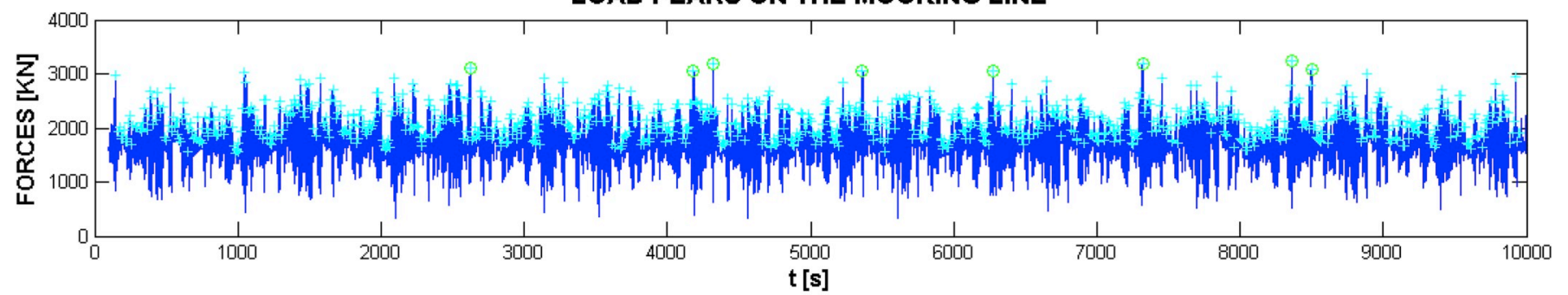

SELECTION OF LOAD PEAKS ON THE MOORING LINE: $\tau$

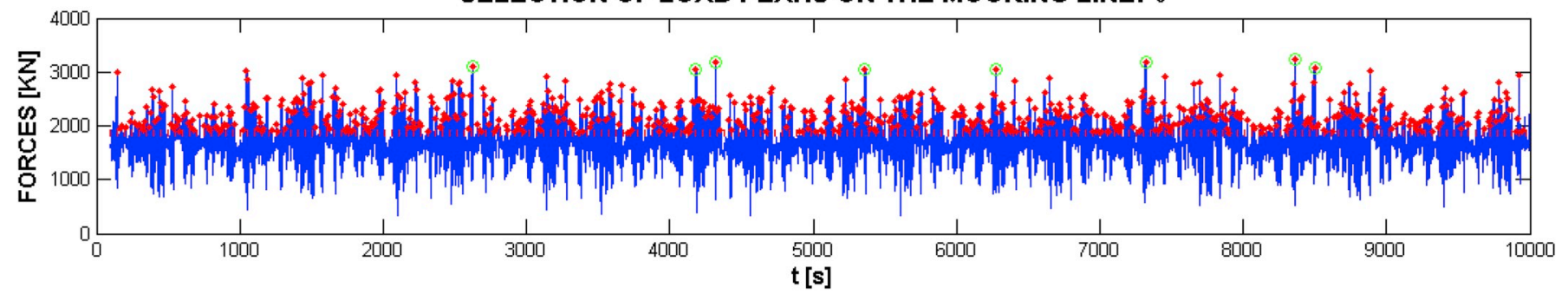

SELECTION OF LOAD PEAKS ON THE MOORING LINE: K

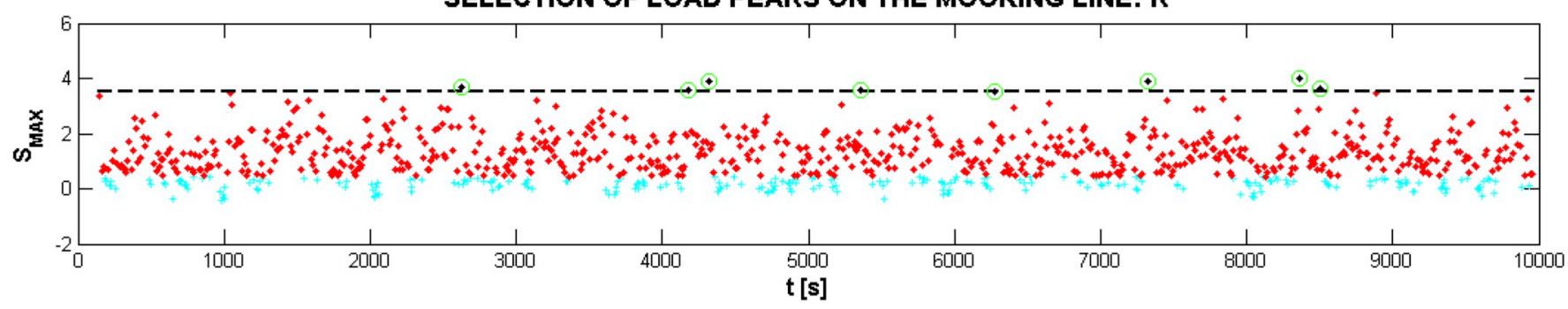

Fig. 8. Selection of load peaks on the mooring line 2.

mooring line. The results presented correspond to the tensions obtained using a dynamic model for a sea state with a significant height of $10.3 \mathrm{~m}$, peak period of $17 \mathrm{~s}$ and wind speed of $25.69 \mathrm{~m} / \mathrm{s}$. The percentages of the peak loads are shown in Table 3 and Table 4 .

The two analysis show that if the $\mathrm{K}$ and $\tau$ parameters are low, the number of peaks increases and vice versa. The percentage of peak loads is more dependent on the $\tau$ parameter in the least loaded line (mooring line 1) than on K. For a value of $\tau$, the number of peaks is the same regardless of the $\mathrm{K}$ parameter. However, the results show that $\mathrm{K}$ parameter is more important in the most loaded line (mooring line 2) than $\tau$ parameter because for a given $\mathrm{K}$ value, the number of peaks remains constant regardless of the value of $\tau$. Load distribution functions for different $\tau$ and $\mathrm{K}$ values are displayed in Fig. 7. A first selection is made to set $\tau$ to a value that would allow for the construction of a representative distribution function of all mooring line loads. A value of $\tau=1.1$ is selected. Subsequently, another selection based on a parametric analysis of $\mathrm{K}$ allows for the construction of different distribution functions of extreme peak loads. A value of $\mathrm{K}=3.5$ allows for the selection of a sufficient number of peak loads to define a representative extreme function.

Next, the selection of peak loads for sea state 3-case 2 is detailed (Table 3). Fig. 8 shows the load time series and the selection of peak loads for mooring line 2. The figure is divided into three panels. The first represents the load time series, highlighting all peaks on the mooring line as points with crosses $(+)$. The second includes a preselection of the peak loads indicated by points (.) applying the $\tau$ parameter threshold. Finally, from the K parameter threshold, the peak loads generated by the sea state considered are selected as circles represented in the third panel.

Table 3

Sensitivity analysis for the mooring line 1: Percentage of peak loads.

\begin{tabular}{|c|c|c|c|c|c|c|c|c|c|c|c|c|}
\hline \multirow[t]{2}{*}{$\tau$} & \multicolumn{12}{|l|}{$\mathrm{K}$} \\
\hline & 0 & 0.5 & 1 & 1.5 & 2 & 2.5 & 3 & 3.5 & 4 & 4.5 & 5 & 5.5 \\
\hline 1 & 100 & 70.55 & 44.82 & 28.32 & 18.12 & 9.71 & 4.85 & 2.10 & 1.13 & 0.97 & 0.65 & 0.65 \\
\hline 1.1 & 33.17 & 33.17 & 33.17 & 28.32 & 18.12 & 9.71 & 4.85 & 2.10 & 1.13 & 0.97 & 0.65 & 0.65 \\
\hline 1.2 & 8.58 & 8.58 & 8.58 & 8.58 & 8.58 & 8.58 & 4.85 & 2.10 & 1.13 & 0.97 & 0.65 & 0.65 \\
\hline 1.3 & 1.13 & 1.13 & 1.13 & 1.13 & 1.13 & 1.13 & 1.13 & 1.13 & 1.13 & 0.97 & 0.65 & 0.65 \\
\hline 1.4 & 0.65 & 0.65 & 0.65 & 0.65 & 0.65 & 0.65 & 0.65 & 0.65 & 0.65 & 0.65 & 0.65 & 0.65 \\
\hline 1.5 & 0.49 & 0.49 & 0.49 & 0.49 & 0.49 & 0.49 & 0.49 & 0.49 & 0.49 & 0.49 & 0.49 & 0.49 \\
\hline 2 & 0.00 & 0.00 & 0.00 & 0.00 & 0.00 & 0.00 & 0.00 & 0.00 & 0.00 & 0.00 & 0.00 & 0.00 \\
\hline 2.5 & 0.00 & 0.00 & 0.00 & 0.00 & 0.00 & 0.00 & 0.00 & 0.00 & 0.00 & 0.00 & 0.00 & 0.00 \\
\hline 3 & 0.00 & 0.00 & 0.00 & 0.00 & 0.00 & 0.00 & 0.00 & 0.00 & 0.00 & 0.00 & 0.00 & 0.00 \\
\hline
\end{tabular}


Table 4

Sensitivity analysis for the mooring line 2: Percentage of peak loads.

\begin{tabular}{|c|c|c|c|c|c|c|c|c|c|c|c|c|}
\hline \multirow[t]{2}{*}{$\tau$} & \multicolumn{12}{|l|}{$\mathrm{K}$} \\
\hline & 0 & 0.5 & 1 & 1.5 & 2 & 2.5 & 3 & 3.5 & 4 & 4.5 & 5 & 5.5 \\
\hline 1 & 100 & 81.22 & 50.59 & 29.27 & 16.92 & 11.00 & 6.94 & 3.21 & 1.69 & 0.85 & 0.34 & 0.00 \\
\hline 1.1 & 90.86 & 81.22 & 50.59 & 29.27 & 16.92 & 11.00 & 6.94 & 3.21 & 1.69 & 0.85 & 0.34 & 0.00 \\
\hline 1.2 & 79.86 & 79.86 & 50.59 & 29.27 & 16.92 & 11.00 & 6.94 & 3.21 & 1.69 & 0.85 & 0.34 & 0.00 \\
\hline 1.3 & 62.44 & 62.44 & 50.59 & 29.27 & 16.92 & 11.00 & 6.94 & 3.21 & 1.69 & 0.85 & 0.34 & 0.00 \\
\hline 1.4 & 46.87 & 46.87 & 46.87 & 29.27 & 16.92 & 11.00 & 6.94 & 3.21 & 1.69 & 0.85 & 0.34 & 0.00 \\
\hline 1.5 & 35.36 & 35.36 & 35.36 & 29.27 & 16.92 & 11.00 & 6.94 & 3.21 & 1.69 & 0.85 & 0.34 & 0.00 \\
\hline 2 & 9.81 & 9.81 & 9.81 & 9.81 & 9.81 & 9.81 & 6.94 & 3.21 & 1.69 & 0.85 & 0.34 & 0.00 \\
\hline 2.5 & 1.69 & 1.69 & 1.69 & 1.69 & 1.69 & 1.69 & 1.69 & 1.69 & 1.69 & 0.85 & 0.34 & 0.00 \\
\hline 3 & 0.00 & 0.00 & 0.00 & 0.00 & 0.00 & 0.00 & 0.00 & 0.00 & 0.00 & 0.00 & 0.00 & 0.00 \\
\hline
\end{tabular}

\section{Results}

Results are described next, including the definition of sea states, the validation of the numerical model and the analysis of loads on the mooring system.

\subsection{Definition of sea states}

In this section, the results of the two different methods proposed for the definition of the sea states are presented: 1) severe sea state selection based on I-FORM (section 3.1.1) and 2) the selection of a set of sea states given by local measurements (section 3.1.2). Based on these two data sets, the importance of wave history and spectral shape will be analysed.

\subsubsection{Severe sea state definition: on the importance of wave history}

Assessment of long-term metocean conditions is evaluated by means of I-FORM (Madsen et al., 1986; Haver and Winterstein, 2008; DNV-RPC205, 2014; Del Jesus et al., 2015). The significant wave height (Hs) is used as the marginal variable in this study using a lognormal distribution function. The peak period (Tp) is adjusted with a normal distribution function and wind velocity at $90 \mathrm{~m}$ over the surface (W) according to a Weibull distribution function. Finally, I-FORM is applied for different return periods. The results are presented in Fig. 9.

The selection of the sea states simulated is shown in Table 5. According to the offshore standard (DNV-OS-J101, 2014), the sea states selected for FOWT must have a 50 year return period. Four wind velocities are simulated in response to cases with single generator-torque control $(7.93 \mathrm{~m} / \mathrm{s})$, single blade-pitch control $(16.08 \mathrm{~m} / \mathrm{s}$ and $25.69 \mathrm{~m} /$ s) and intermediate situations $(11.93 \mathrm{~m} / \mathrm{s})$. The concomitant wave heights with these velocities are obtained from Fig. 9, which also considers cases with short and long periods for each situation. In addition, the case involving a higher wave height is also selected. A total of seven sea states are analysed.

Twenty cases or iterations for each sea state are generated using a JONSWAP spectrum with gamma 3.3 to investigate the effect of wave groupiness on the loads on the mooring lines. These iterations also contribute to obtain a good definition of the maximum wave height. The same wind velocity time series is used in all cases to capture the importance of the wave history. The length of the series is $10000 \mathrm{~s}$. Therefore, each sea state is long enough to be statistically representative. The wave generation is obtained with an in-house code (Lara et al., 2006) developed by IHCantabria, and the wind generation is obtained by the TurbSim code (Jonkman and Kilcher, 2012). The following parameters are analysed to highlight differences between each case generated:

a) Statistical parameters: mean wave height $(\mathrm{Hm})$, standard deviation wave height (Hstd), root mean square wave height (Hrms), significant wave height $(\mathrm{Hs})$, mean of the fifty highest waves $\left(\mathrm{H}_{50}\right)$, mean of the ten highest waves $\left(\mathrm{H}_{10}\right)$, maximum wave height (Hmax), mean crest value (Hp_m), significant crest value (Hp_s), maximum crest $(\mathrm{HpM})$, mean trough value (Hn_m), significant trough value $\left(\mathrm{Hn}_{-} \mathrm{s}\right)$, minimum trough $(\mathrm{HnM})$, mean period $(\mathrm{Tm})$, significant period (Ts) and $\mathrm{Hmax} / \mathrm{Hm} 0$.

b) Spectral parameters: significant wave height from zero-order moment $(\mathrm{Hm} 0)$, peak period $(\mathrm{Tp})$, spectral period with $\mathrm{n}=1(\mathrm{Tm} 01)$ and spectral period with $\mathrm{n}=2$ (Tm02).

An analysis of these parameters is presented in Fig. 10. In particular, these parameters correspond to sea state 6 . This figure reveals that, as expected, aggregated parameters have limited variability, while other individual indicators such as Hmax show significant variability. In addition, the wave time history analysis and the comparison of the computed spectra of certain cases to sea state 6 is presented in Fig. 11. It is demonstrated that, from an energy point of view, all cases show similar characteristics.

\subsubsection{Synthetic versus observed sea spectra: on the importance of spectral shape}

From an instrumental database located in BIMEP, four sea states (Fig. 12) are selected, taking into account the shape of the spectrum from the database of the ANTEIA buoy. Two are swell sea states (sea state 1 and sea state 2 ), one is a wind sea state (sea state 3 ) and the last is a calm sea state (sea state 4). It is worth noting that energy is higher in swell seas than in other seas. In addition, it is important to highlight the difference in the shape of the wind sea spectrum with respect to the theoretical ones due to the presence of two peaks.

The main objective of this research is to analyse the influence of the spectra definition on the mooring line loads. To this end, different spectral definitions are proposed. In Fig. 12, the continuous line represents the buoy spectrum, and the dashed and dotted lines represent the JONSWAP with gamma 3.3 and JONSWAP with the best gamma fit, respectively. It can be observed that the JONSWAP spectrum does not adequately represent the measured spectra with more than one peak. This effect will be investigated with respect to the loads on the mooring system.

Considering that the ANTEIA buoy only measures waves, data provided by the WAVESCAN buoy are used to obtain the wind velocity concomitant with the selected sea states at $90 \mathrm{~m}$ over the surface. Therefore, the most realistic representation of local sea states is achieved. The characteristics of the selected sea states are presented in Table 6. According to the data provided in Table 6, different random synthetic wave and wind time series are generated for each database. Table 7 shows the target parameters and the real parameters obtained for each approach and sea state. It should be noted that, thanks to the ANTEIA buoy, the Hmax is known. Based on Hmax and other aggregated parameters, a representative sea state has been reconstructed for each wave spectrum method. 


\section{Lognormal distribution [Hs] \& Normal distribution [Tp]}

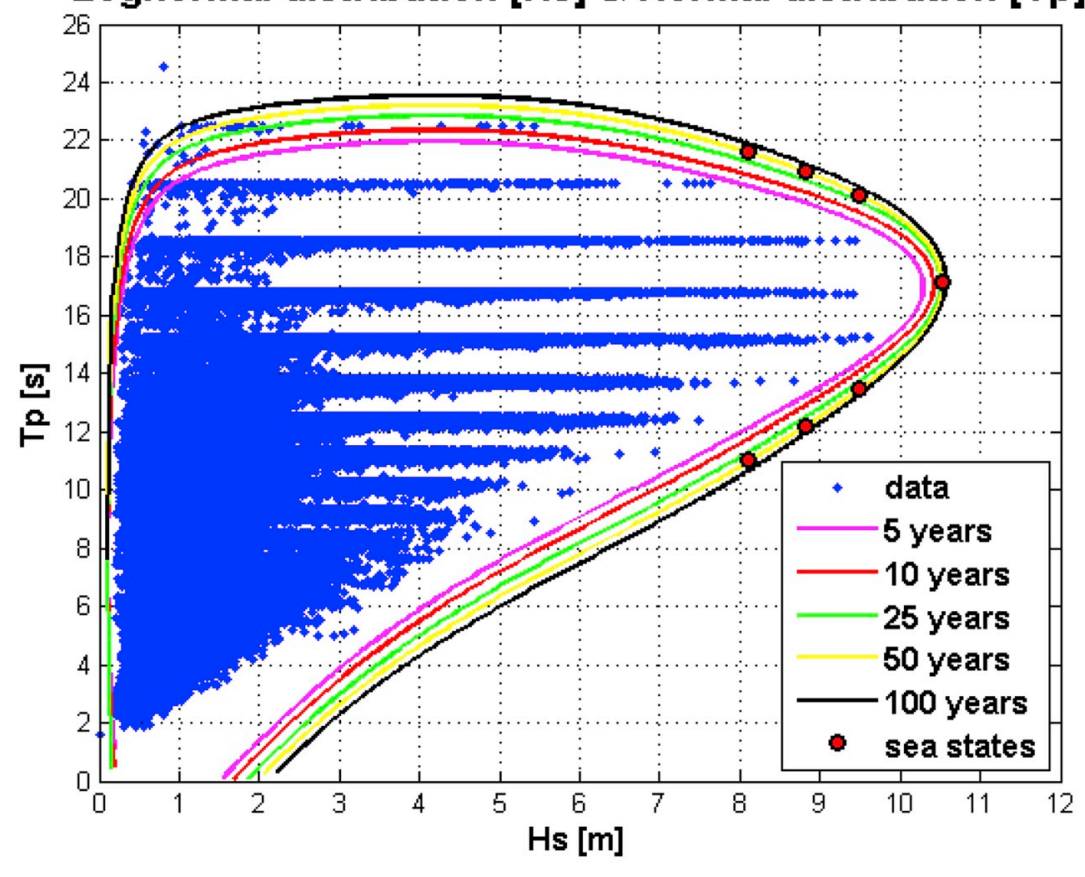

a) $\mathrm{Hs}[\mathrm{m}]$

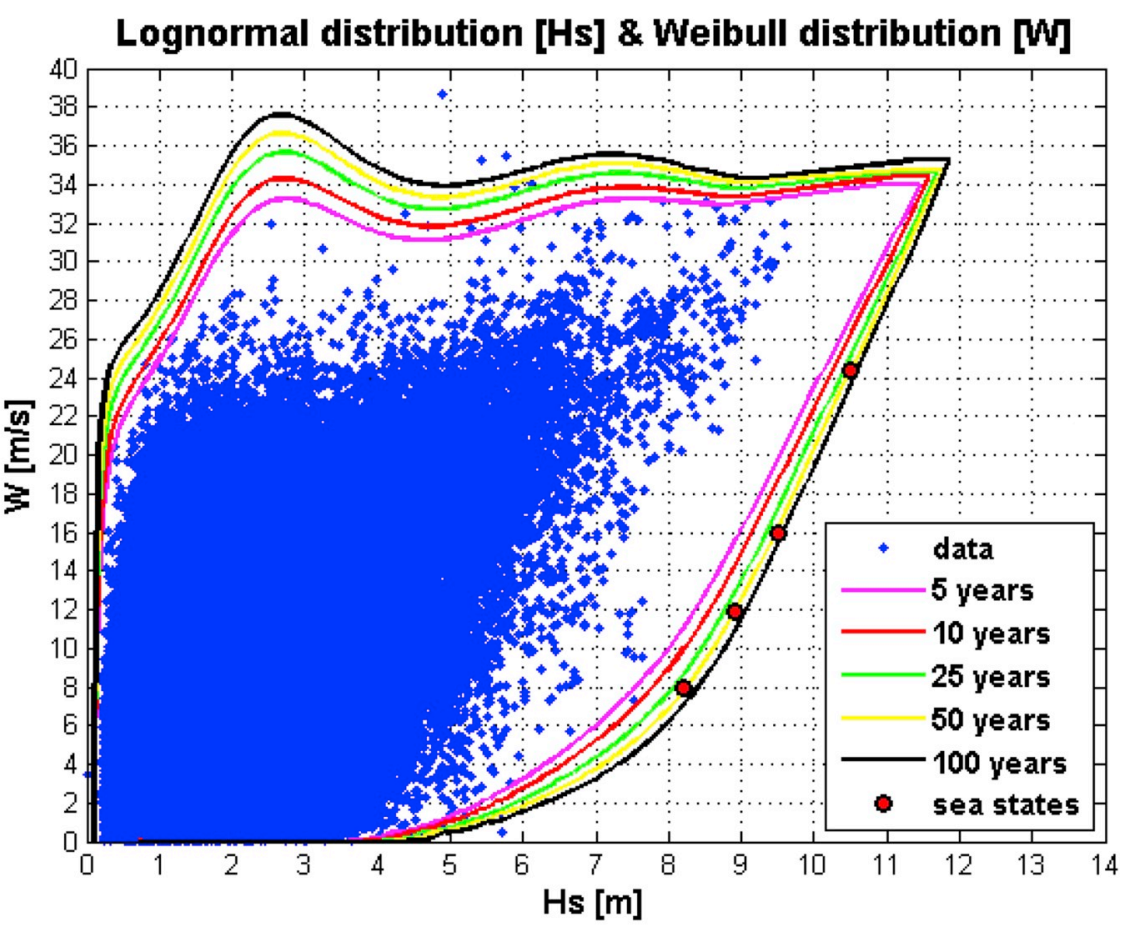

Fig. 9. Evaluation of metocean data for different return periods: a) Hs \& Tp b) Hs \& W.

Table 5

Sea state characteristics.

\begin{tabular}{llll}
\hline SEA STATE & Hs $(\mathrm{m})$ & Tp $(\mathrm{s})$ & $\mathrm{W}(\mathrm{m} / \mathrm{s})$ \\
\hline 1 & 8.10 & 11.20 & 7.93 \\
2 & 8.10 & 21.50 & 7.93 \\
3 & 8.81 & 12.50 & 11.93 \\
4 & 8.81 & 20.80 & 11.93 \\
5 & 9.50 & 13.90 & 16.08 \\
6 & 9.50 & 19.80 & 16.08 \\
7 & 10.30 & 17.00 & 25.69 \\
\hline
\end{tabular}

\subsection{Validation of floating wind turbine model}

The numerical model built for the time domain simulation (described in section 2.4) of the FOWT has been validated against laboratory tests performed by the Maritime Research Institute Netherlands (MARIN) in 2013 and published in the context of the OC5 Project (Robertson et al, 2014; Robertson et al, 2017). A complete calibration and validation are performed based on results pertaining to static tension, decay tests and regular and irregular waves with and without wind. The results are validated along the zero degrees direction comparing the movements (surge, heave and pitch) in the platform and the 

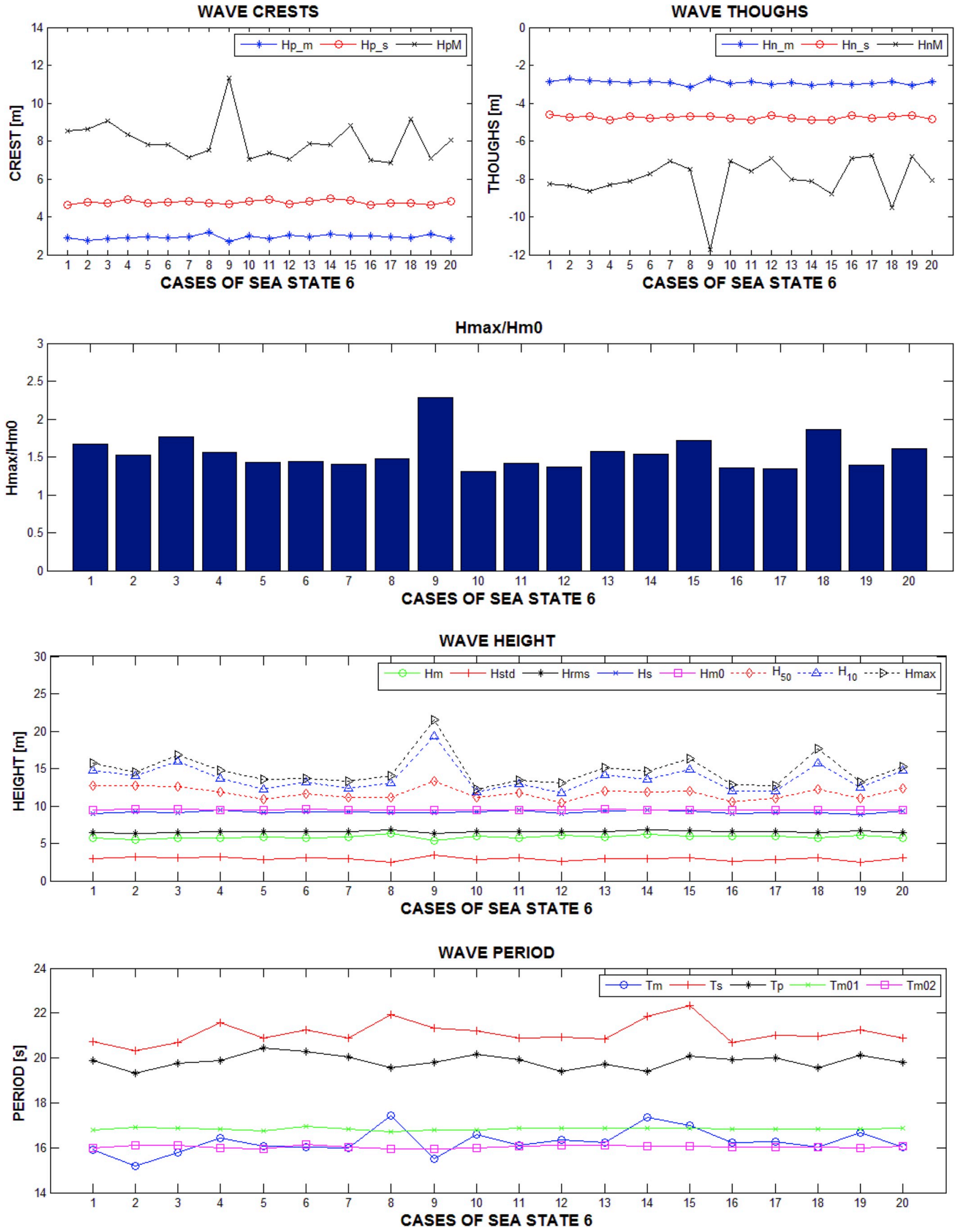

Fig. 10. Parameters for the cases of sea state 6 . 
CASE 2

\begin{tabular}{c} 
军 \\
\hline
\end{tabular}

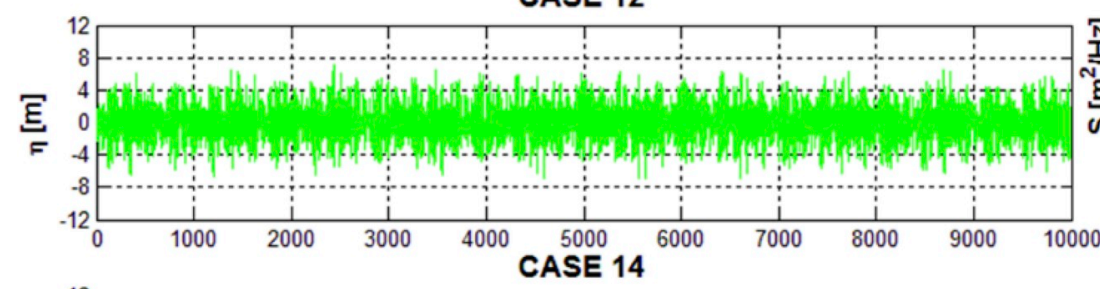

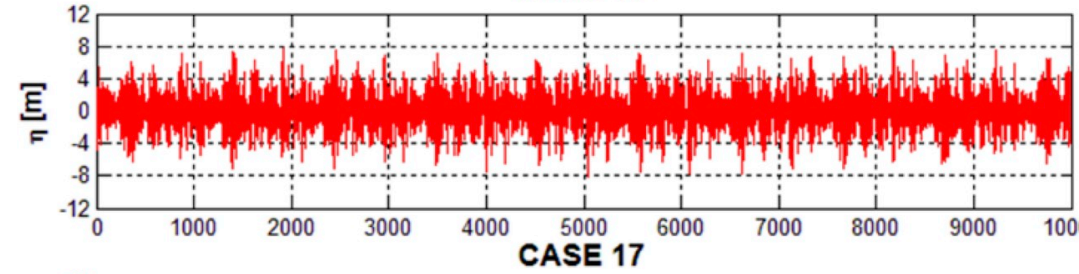

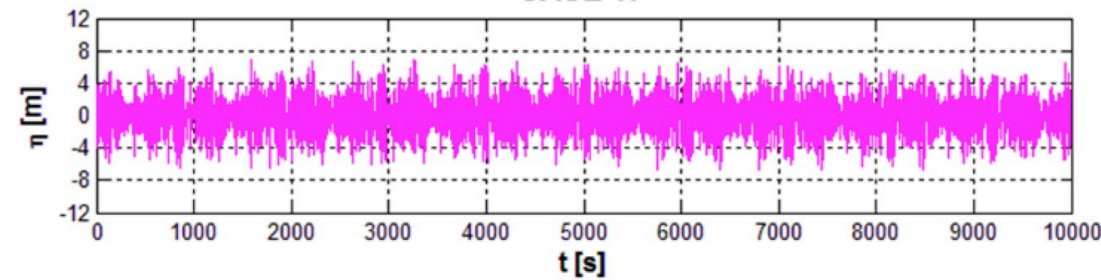

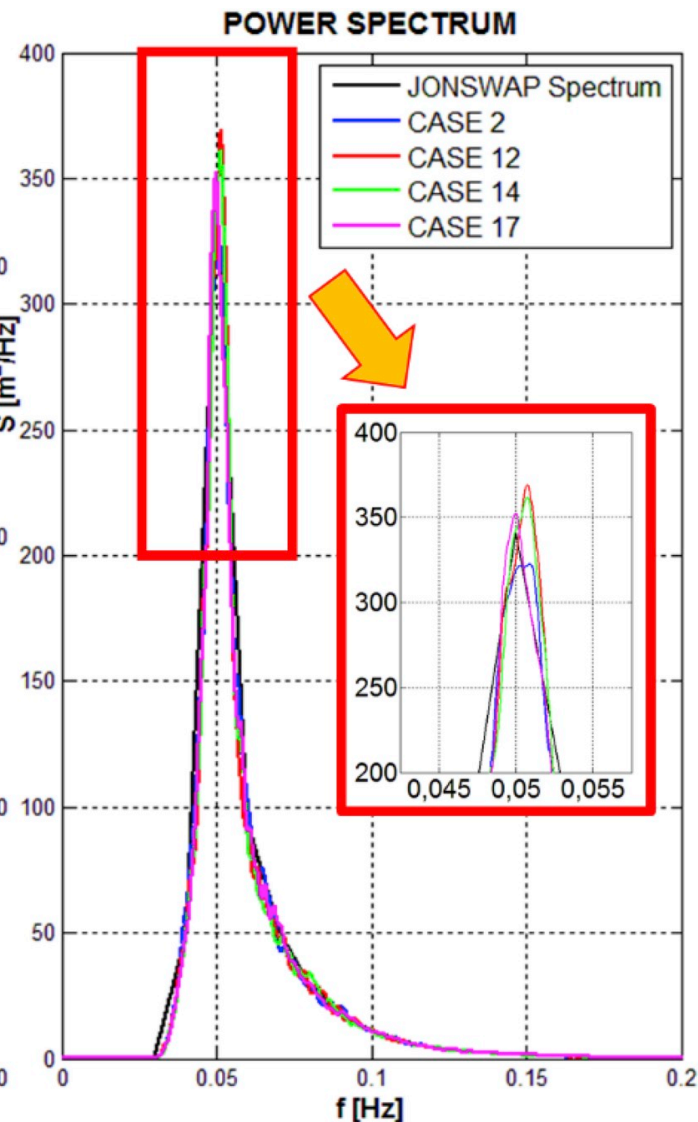

Fig. 11. Wave time history for certain cases of sea state 6 .
SEA STATE 1

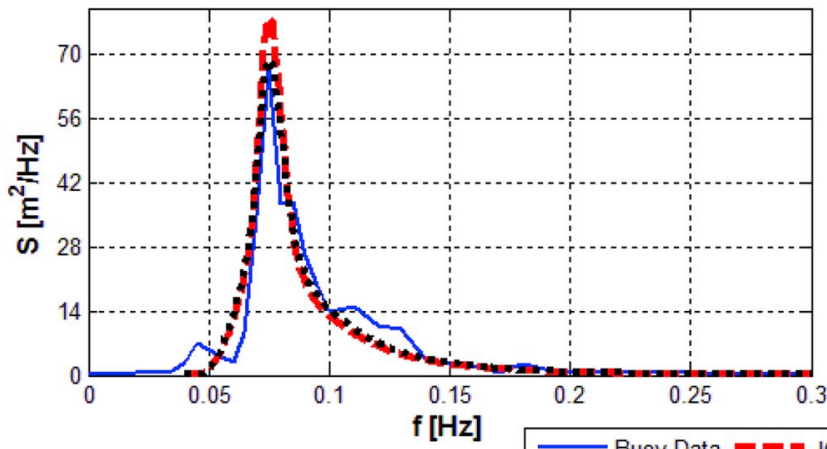

SEA STATE 3

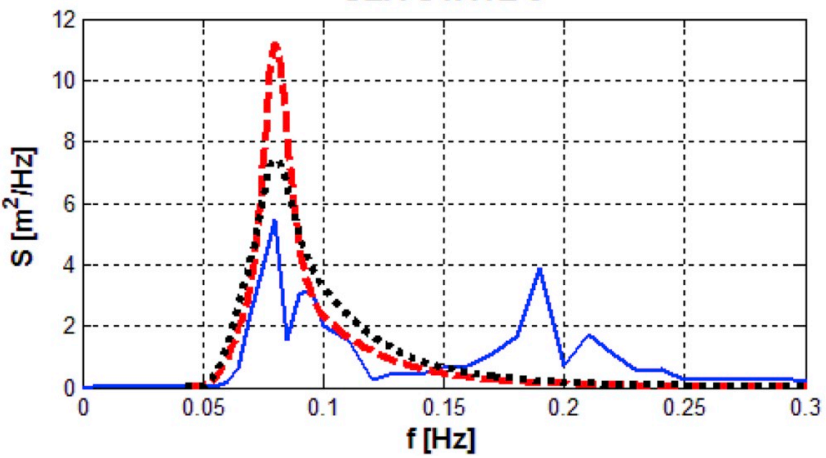

SEA STATE 2

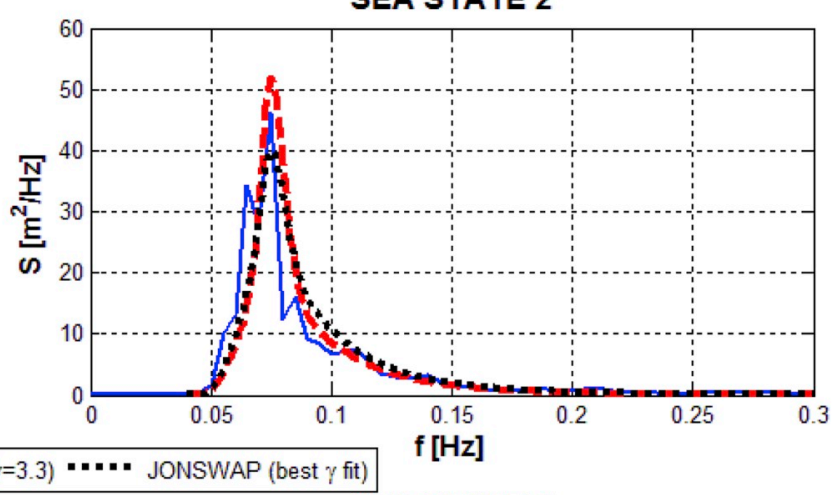

SEA STATE 4

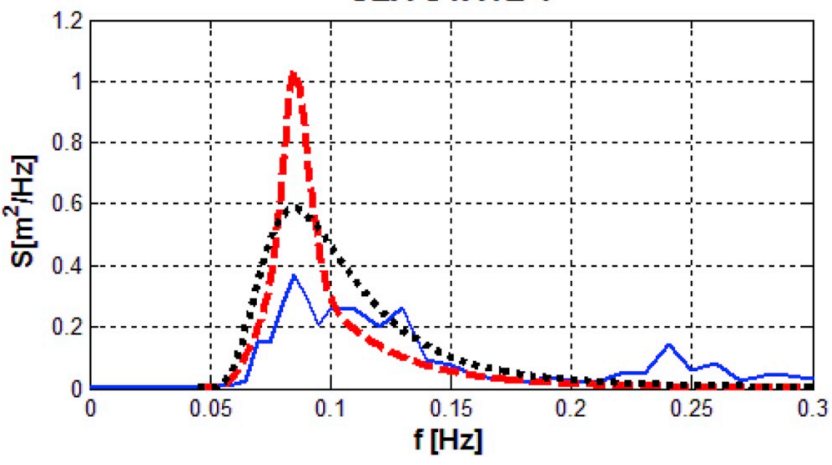

Fig. 12. Wave spectra obtained by different approaches. 
Table 6

Metocean parameters from the different sea states.

\begin{tabular}{|c|c|c|c|c|c|c|c|}
\hline SEA STATE & $\mathrm{Tp}(\mathrm{s})$ & $\mathrm{Hm} 0(\mathrm{~m})$ & $\operatorname{Hmax}(\mathrm{m})$ & $\mathrm{W}(\mathrm{m} / \mathrm{s})$ & Date & hour & $\gamma$ best fit \\
\hline 1 & 13.33 & 5.56 & 9.98 & 8.59 & $27 / 02 / 2017$ & $23: 32$ & 2.63 \\
\hline 2 & 13.33 & 4.53 & 7.50 & 8.40 & 06/03/2017 & $21: 02$ & 2.07 \\
\hline 3 & 12.50 & 2.17 & 3.42 & 9.96 & $03 / 03 / 2017$ & $17: 02$ & 1.55 \\
\hline 4 & 11.76 & 0.68 & 1.12 & 1.56 & $13 / 04 / 2017$ & $6: 32$ & 1.01 \\
\hline
\end{tabular}

Table 7

Metocean parameters from the different sea states.

\begin{tabular}{|c|c|c|c|c|c|c|c|c|c|c|c|c|}
\hline \multirow[t]{2}{*}{ SEA STATE } & \multicolumn{3}{|c|}{ TARGET } & \multicolumn{3}{|l|}{ BUOY } & \multicolumn{3}{|c|}{ JONSWAP 3.3} & \multicolumn{3}{|c|}{ JONSWAP BEST FIT } \\
\hline & $\mathrm{Tp}(\mathrm{s})$ & $\mathrm{Hm0}(\mathrm{m})$ & $\operatorname{Hmax}(\mathrm{m})$ & $\mathrm{Tp}(\mathrm{s})$ & $\mathrm{Hm0}(\mathrm{m})$ & $\operatorname{Hmax}(\mathrm{m})$ & $\mathrm{Tp}(\mathrm{s})$ & $\mathrm{Hm0}(\mathrm{m})$ & $\operatorname{Hmax}(\mathrm{m})$ & $\operatorname{Tp}(\mathrm{s})$ & $\mathrm{Hm0}(\mathrm{m})$ & $\operatorname{Hmax}(\mathrm{m})$ \\
\hline 1 & 13.33 & 5.56 & 9.98 & 12.79 & 5.46 & 9.66 & 12.73 & 5.43 & 9.72 & 13.04 & 5.52 & 9.60 \\
\hline 2 & 13.33 & 4.53 & 7.50 & 13.51 & 4.45 & 7.19 & 13.80 & 4.44 & 7.27 & 13.44 & 4.62 & 7.31 \\
\hline 3 & 12.50 & 2.17 & 3.42 & 12.66 & 2.17 & 3.48 & 12.48 & 2.15 & 3.29 & 12.79 & 2.22 & 3.26 \\
\hline 4 & 11.76 & 0.68 & 1.12 & 11.60 & 0.71 & 1.14 & 11.45 & 0.68 & 1.13 & 11.60 & 0.71 & 1.14 \\
\hline
\end{tabular}

tension on the mooring lines. The results of this validation for irregular waves with and without wind are presented in Figs. 13-16.

The agreement between the code and laboratory tests in terms of movements and tensions is very good. The linear and non-linear damping are calibrated by a superposition of decay tests between the numerical model and laboratory tests. The comparison of natural periods show an accuracy close to $100 \%$ between the code and the experimental results. Regular wave tests are predicted in terms of the platform movements and tensions on the mooring lines in the region of 95\%. Similar discrepancies reported in (Hall and Goupee, 2015) are obtained with respect to movements with irregular waves. These discrepancies are attributed to the influence of the different approaches adopted in the hydrodynamic models. The model developed in this study neglects viscous forces and the second-order potential. For this reason, the model does not capture the low-frequency energy in surge properly. However, the load results on the mooring lines are more than acceptable, as demonstrated by the comparison of the load time series and the spectra. The results obtained support the aims of this article.

\subsection{Analysis of loads on the mooring lines}

In the present subsection, the analysis of mooring performance is discussed. Three studies are carried out. First, the importance of dynamic modelling to the mooring line design is discussed in section 3.3.1. Second, the influence of wave time history on mooring loads, analysed by statistical techniques, is discussed and safety factors are proposed in section 3.3.2. Finally, the influence of spectral shape on mooring loads is discussed in section 3.3.3.

\subsubsection{The importance of dynamic modelling over mooring line performance assessment}

The influence of wave history on the peak loads is analysed using a dynamic and quasi-static model for the seven sea states proposed. A comparison between quasi-static and dynamic model is presented in Fig. 17 for the three mooring lines of the semisubmersible platform. The results correspond to sea state 6 -case 8 . This figure shows the loads in terms of time series and power spectra together with the wave power spectrum. The behaviour between both analyses is very different not only in force magnitude but also energy. In general, the quasi-static model does not properly capture peak loads and underestimates the spectral energy. These results are a consequence of the model limitations by not accounting for inertia, wave forces and seabed dynamic friction (Jonkman and Buhl, 2007). Moreover, different parameters are evaluated to corroborate the differences shown in Fig. 17: the average load time series (T), the average of all crests (Tc), the significant value among all crests (Ts), the maximum crest (Tmax) and the average of selected crests (Tlp) using the load peak method. Fig. 18 shows all these parameters for sea state 6 and the corresponding 20 iterations comparing quasi-static and dynamic tensions. It can be concluded that the mean load differences are approximately 5\%. However, by far the highest discrepancies are obtained for the Tc and Ts parameters in the regions of $30 \%$ and $45 \%$, respectively. Extreme loads are underestimated by the quasi-static model with respect to the dynamic model according to the Tmax and Tlp parameters.

\subsubsection{Influence of wave time series on mooring loads: safety factors}

To evaluate the importance of wave time history, the 20 iterations of sea state 6 are shown in Fig. 18. Although T, Tc and Ts present low discrepancy rates, Tmax and Tlp, which are directly related to mooring line design, show large discrepancies. Differences of up to $57 \%$ in Tmax and $34 \%$ in Tlp are detected in the most extreme sea state (sea state 7) and the most loaded mooring line. This variability justifies the importance of statistical techniques application on mooring line design (DNVGL-OS-E301, 2015).

Moreover, from wave history analysis, it can be concluded that the maximum tension discrepancies are directly related to the distribution of wave groupiness and not to the maximum wave height. The left panel of Fig. 19 shows the instant at which the maximum tension and the height of the maximum wave are produced for all cases of sea state 6 . The maximum wave height and the maximum tension do not coincide so the maximum wave does not generate the maximum load on moorings. Maximum load is generated by the distribution of wave groupiness. This conclusion is reinforced by results shown on the right panel where it can be seen that similar wave heights generate significant load differences on the mooring system. The maximum tension together with the maximum wave height (Hmax), the maximum crest (HpM) and the minimum trough (HnM) are also shown for all cases of sea state 6 on mooring line 2 . Noticeable differences in maximum tensions are observed between the 20 cases. Hence, it is demonstrated that the evaluation of the maximum tension is a complex process and only possible making use of statistical techniques because the maximum tension does not necessarily have to occur simultaneously with the maximum wave height.

To understand extreme mooring load performance, two methodologies are applied to assess the variability of the peak loads. First, the extreme events are identified following the procedure described in section 2.5, and second, the extreme events are characterised according to the maximum local load for each case. 

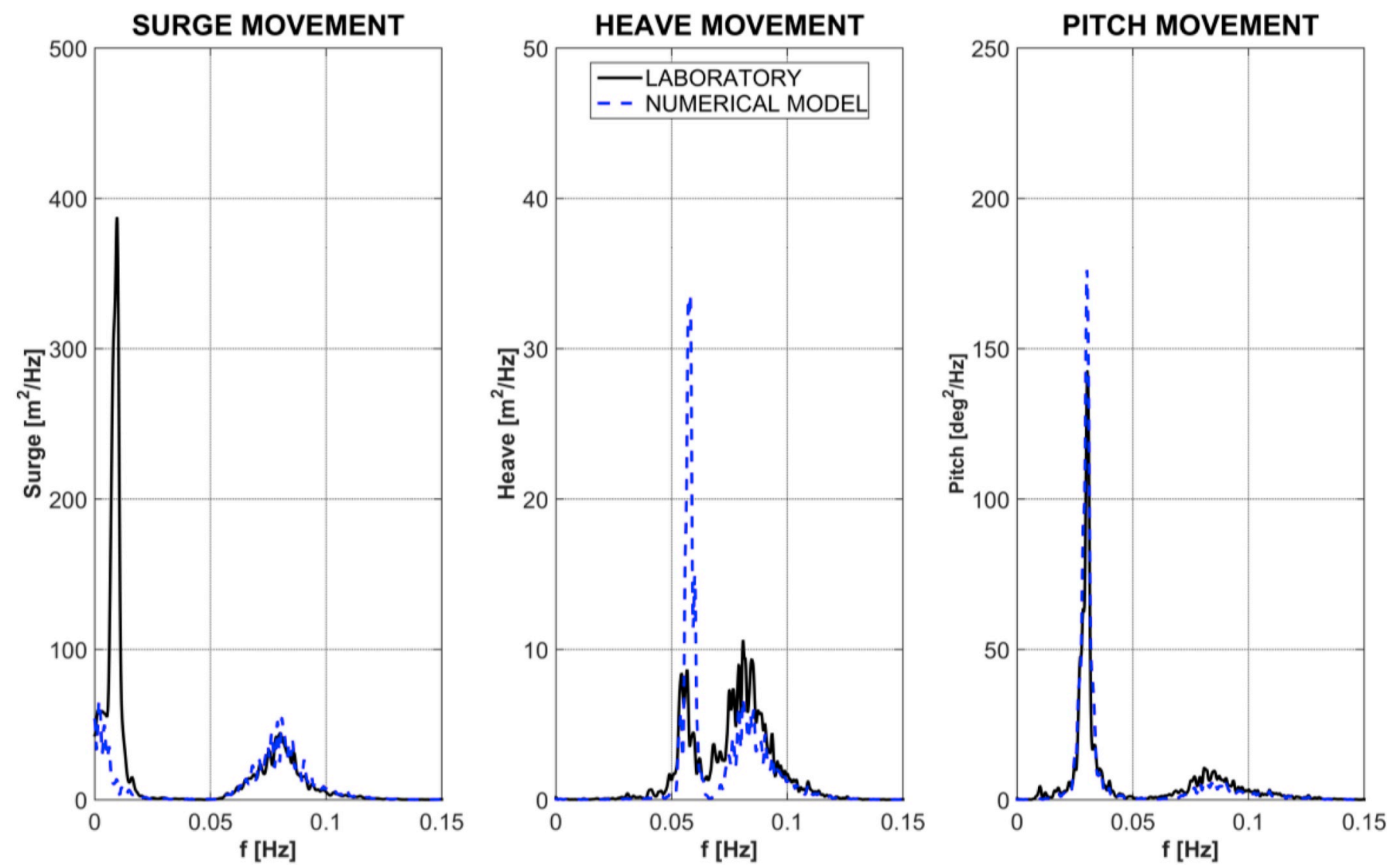

Fig. 13. Irregular wave test ( $\mathrm{Hs}=7.1 \mathrm{~m}, \mathrm{Tp}=12.1 \mathrm{~s}, \gamma=2.2$, JONSWAP spectrum): Movements.
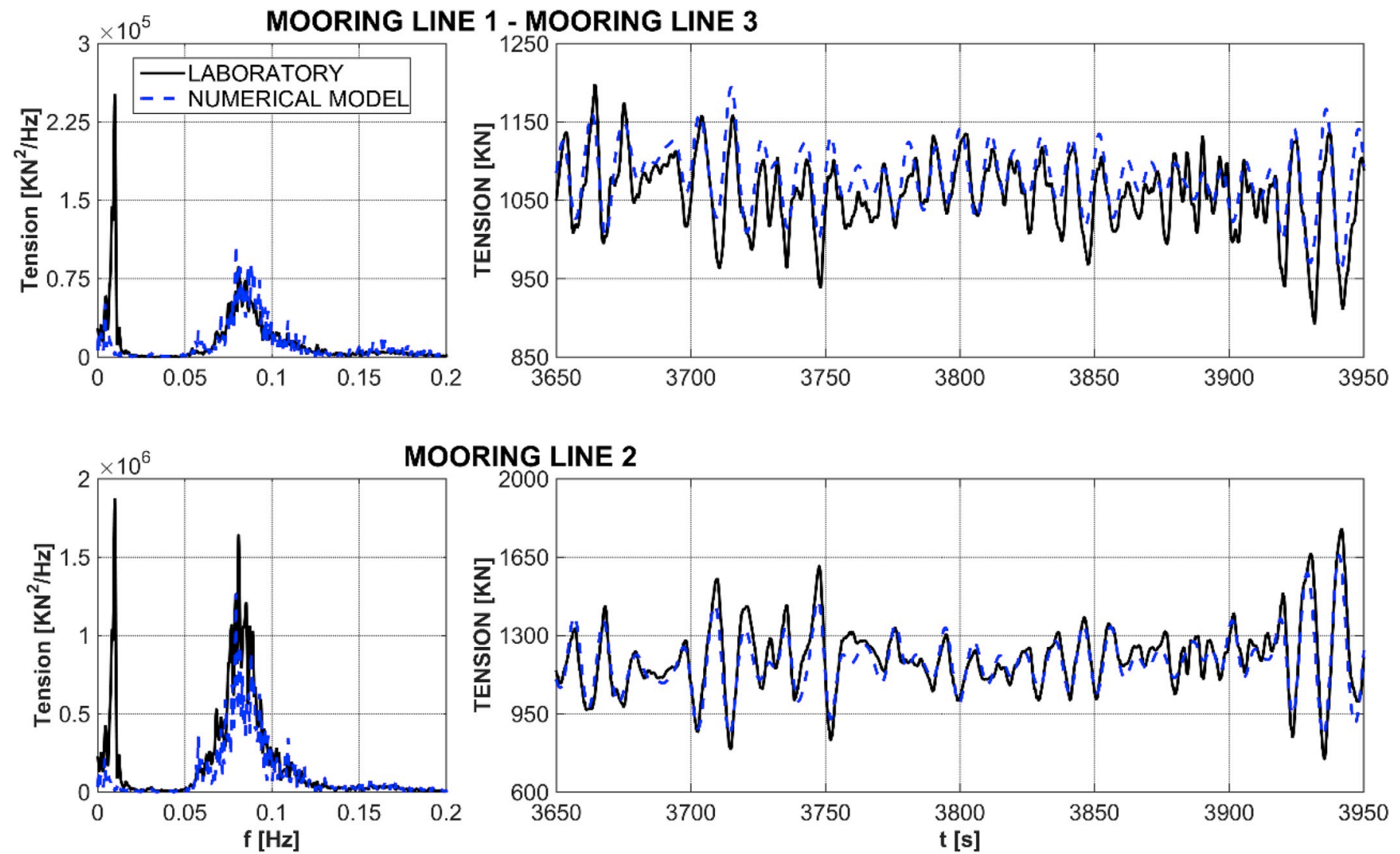

Fig. 14. Irregular wave test $(\mathrm{Hs}=7.1 \mathrm{~m}, \mathrm{Tp}=12.1 \mathrm{~s}, \gamma=2.2$, JONSWAP spectrum): Tensions. 

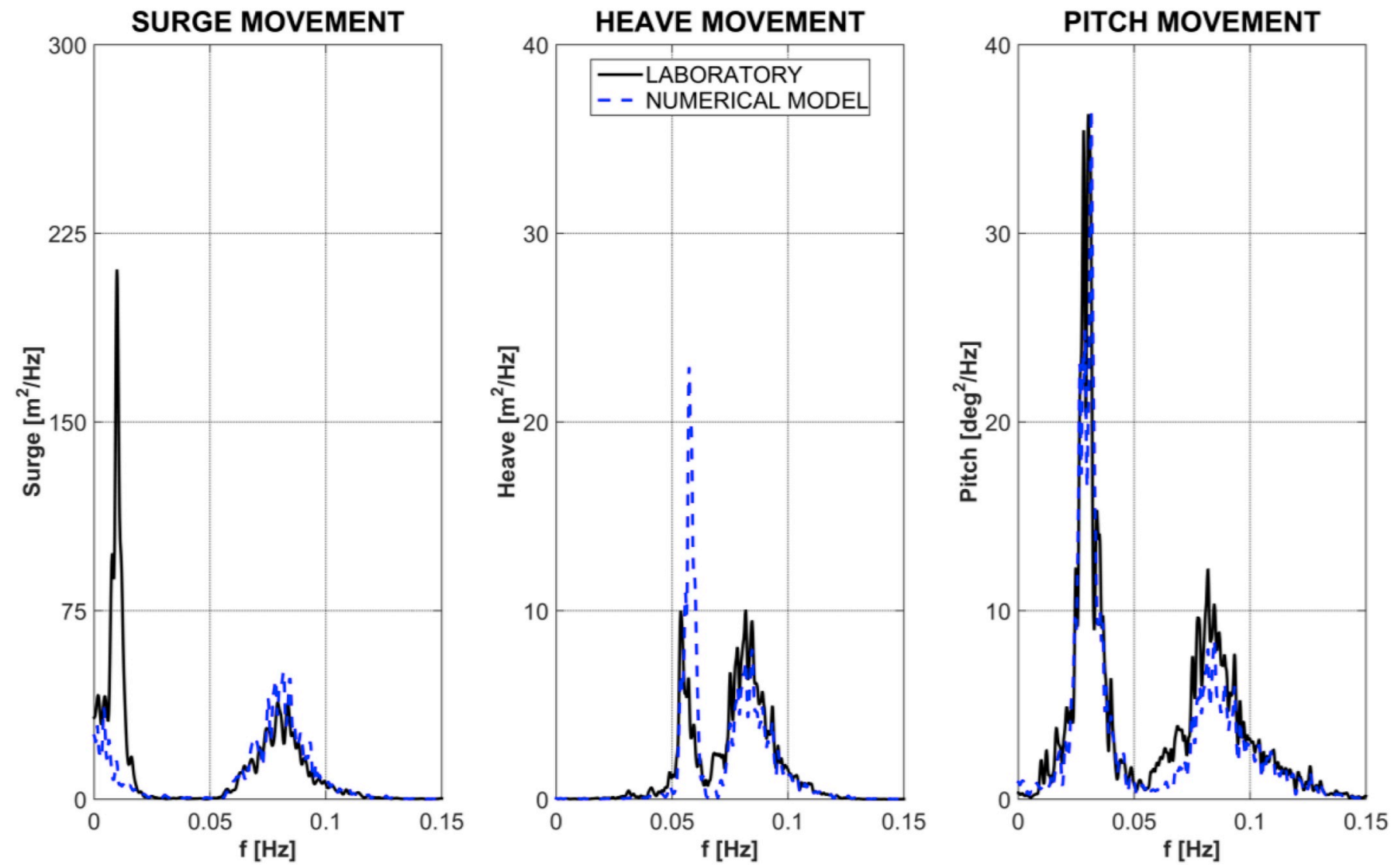

Fig. 15. Operational wave and steady wind (Irregular wave: $\mathrm{Hs}=7.1 \mathrm{~m}, \mathrm{Tp}=12.1 \mathrm{~s}, \gamma=2.2$, JONSWAP; Wind: RPM $=12.1$, W $=12.91$ ): Movements.
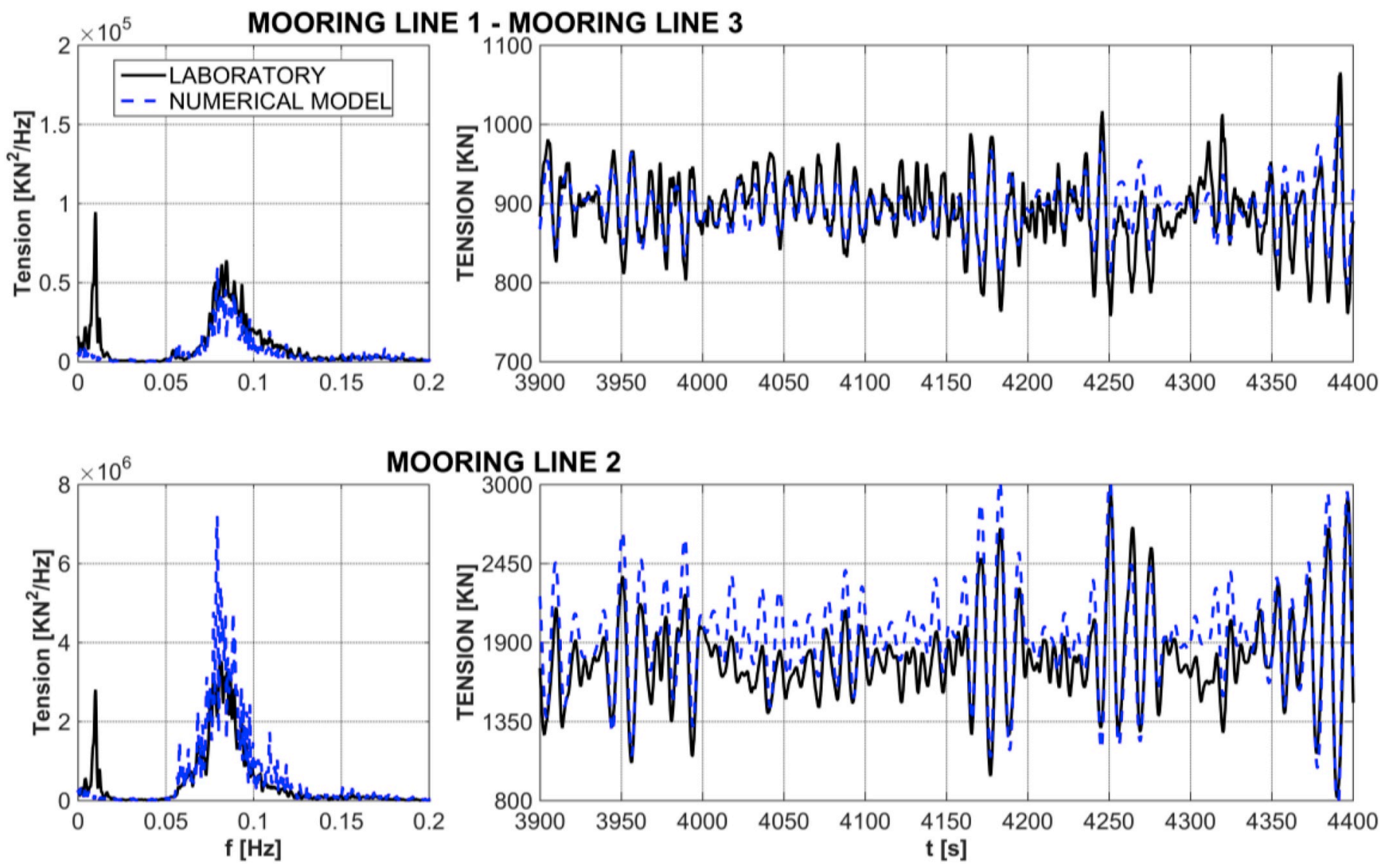

Fig. 16. Operational wave and steady wind (Irregular wave: $\mathrm{Hs}=7.1 \mathrm{~m}, \mathrm{Tp}=12.1 \mathrm{~s}, \gamma=2.2$, JONSWAP; Wind: $\mathrm{RPM}=12.1$, $\mathrm{W}=12.91$ ): Tensions. 

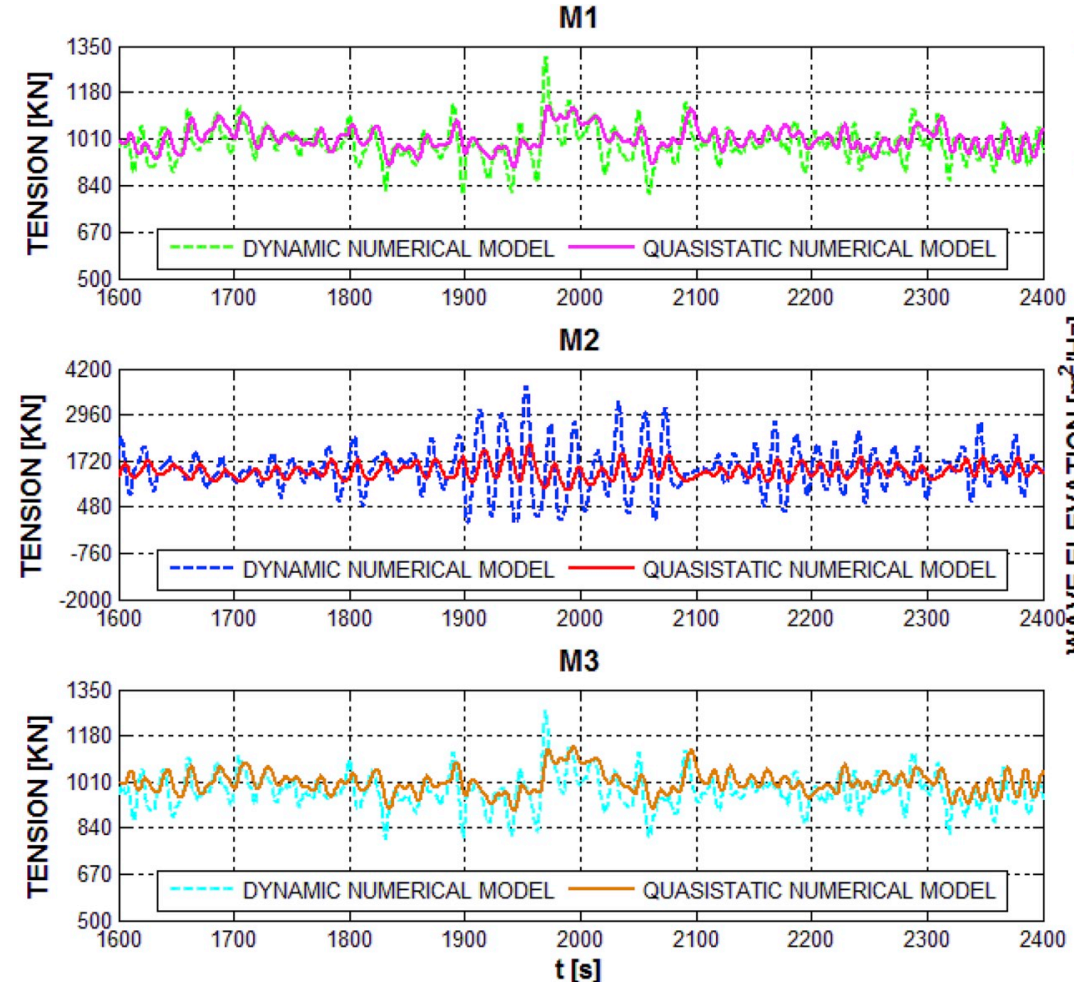

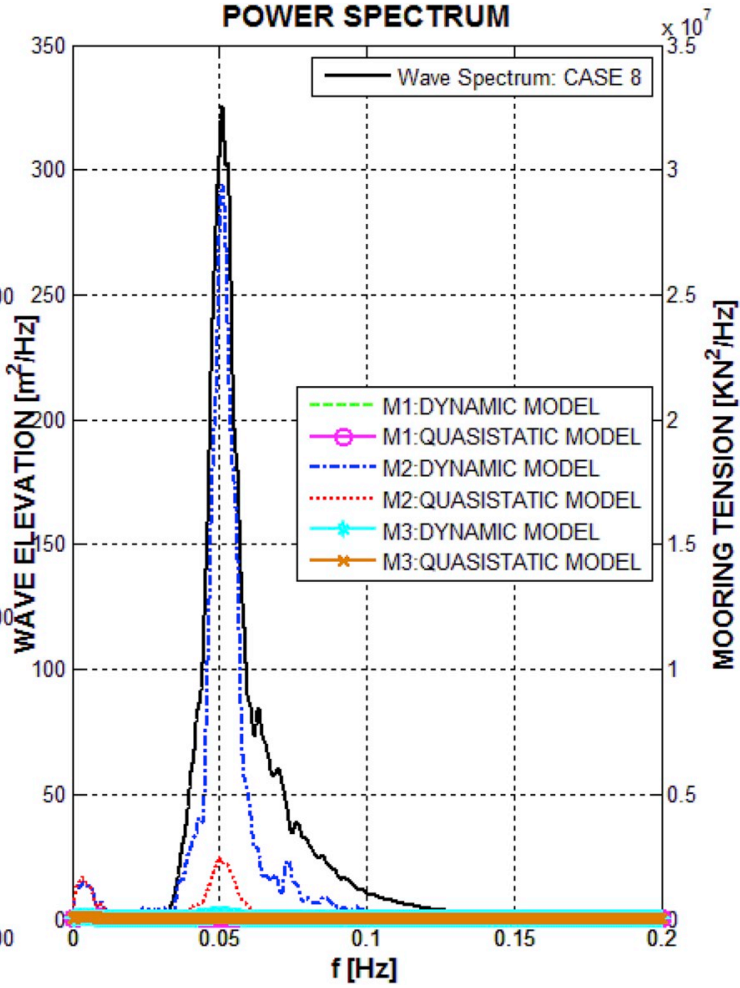

Fig. 17. Comparison of tension between dynamic and quasi-static models: sea state 6-case 8 .

The selection of the load peaks reveals significant variability in the determination of the extreme load. Table 8 summarises the maximum, minimum and difference in percentages for all iterations in each sea state and for each mooring line. Load differences between $6 \%$ and $17 \%$ are obtained for the least loaded line and between $25 \%$ and $40 \%$ for the most loaded line. Discrepancies between $21 \%$ and $28 \%$ and $79 \%$ are obtained for the most extreme sea state.

Loads are fitted using a generalized extreme value (GEV) distribution function for the two studies. This fit is shown in Fig. 20 for the peak load method (a) and for the maximum local load (b). To check the quality of fit, a quantile-quantile plot is generated (QQ plot). The diagnostic quality of this test is very good, with points near the diagonal. Fig. 20 shows the QQ plot for the most loaded mooring line in sea state 6. The most accurate adjustment is achieved by the peak load method to produce more load data as opposed to the maximum local load, in which only 20 data, one per case, are available. Nevertheless, an acceptable correlation coefficient of 0.9872 is obtained.

With respect to mooring design, the DNV mooring standard (DNVGL-OS-E301, 2015) proposes the load evaluated by the most likely value based on the extreme distribution. The most likely value (most probable maximum, MPM) of tensions for each criterion, sea state and mooring line is presented in Table 9. Higher MPM values are obtained by the maximum local load method. In general, differences in the region of $5 \%$ are obtained for all sea states reaching discrepancies of approximately $8 \%$ for the most extreme sea state.

The distribution function enables us to design mooring lines against extreme loads with a high level of probability. However, from designers' point of view, it is more appropriate to employ safety factors taking into account only the mean load on the mooring line. To this end, Table 10 proposes different safety factors obtained for the different
M1

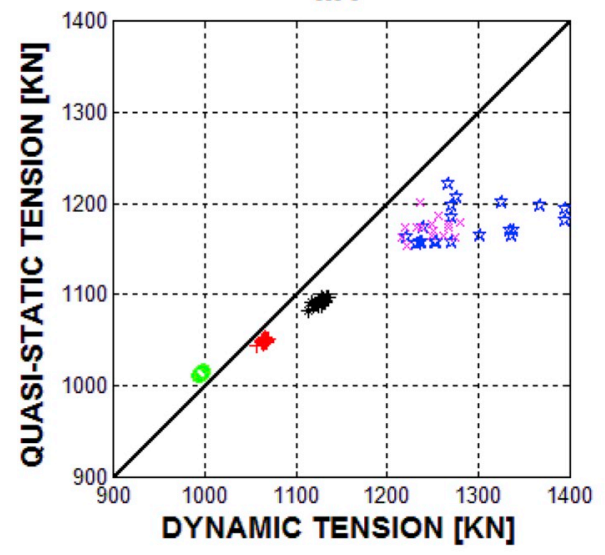

M2

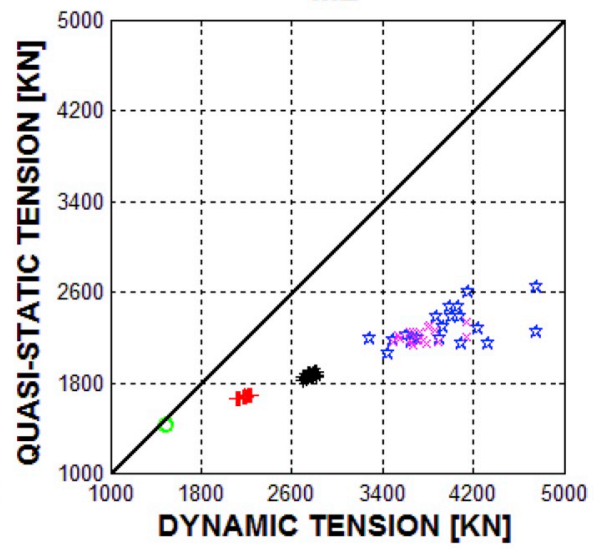

M3

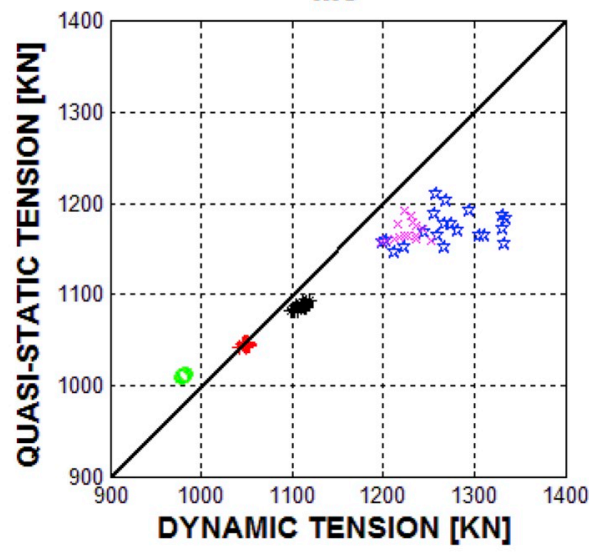

$\mathrm{T}+\mathrm{Tc} * \mathrm{Ts}$ \ $\mathrm{Tmax} \times \mathrm{Tlp}$

Fig. 18. Comparison of different load parameters on the mooring lines: sea state 6 . 

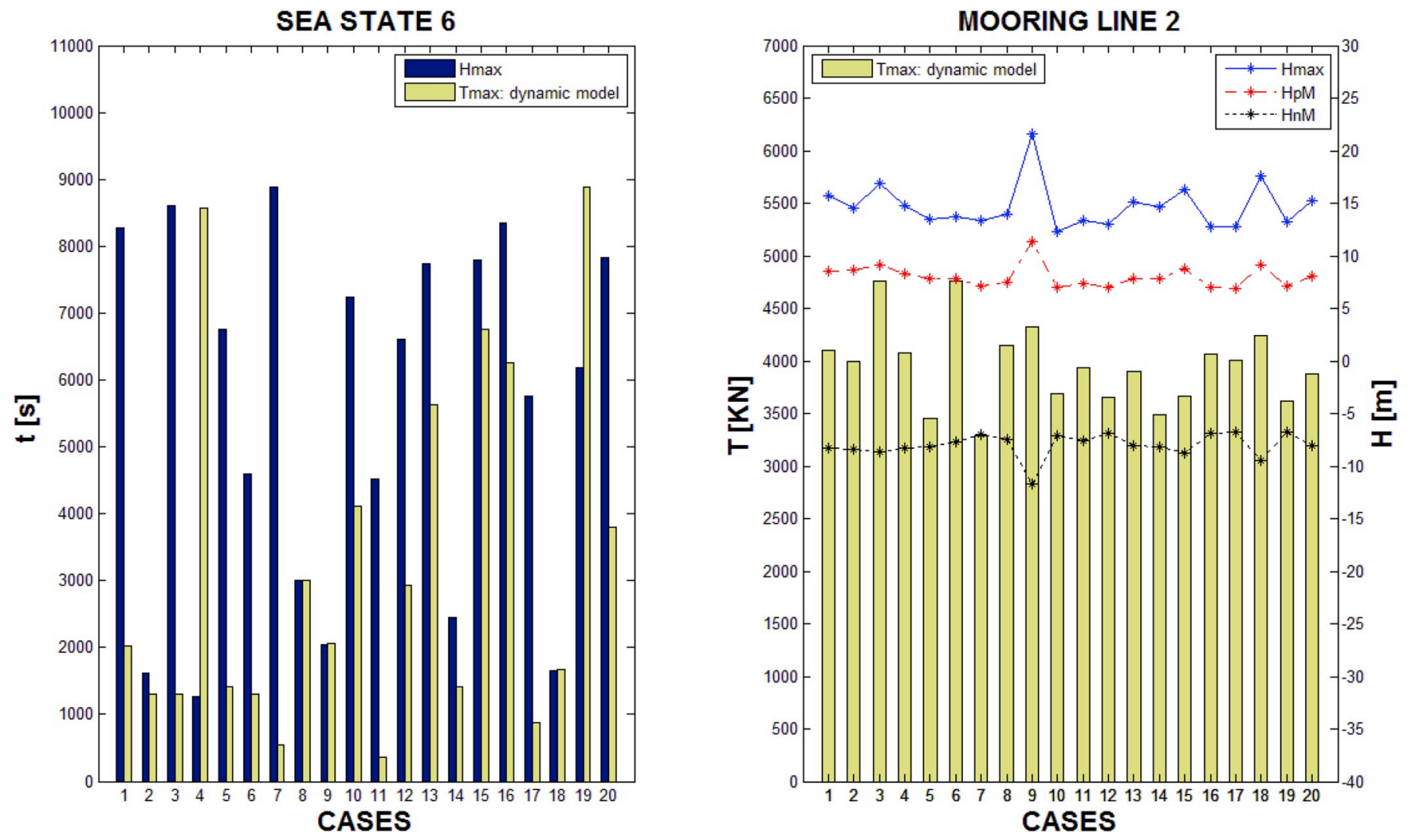

Fig. 19. Number of load peaks on the mooring lines: sea state 6 .

Table 8

Maximum and minimum tension together with the difference (\%) between peak loads for all moorings and sea states.

\begin{tabular}{llllllll}
\hline \multicolumn{2}{l}{ MAXIMUM TENSION (KN) } \\
\hline MOORING LINE & \multicolumn{7}{l}{ SEA STATES } \\
\cline { 2 - 8 } & 1 & 2 & 3 & 4 & 5 & 6 & 7 \\
\hline M1 & 1146 & 1268 & 1199 & 1290 & 1289 & 1396 & 1665 \\
M2 & 3704 & 4347 & 3784 & 4353 & 3900 & 4763 & 5956 \\
M3 & 1137 & 1248 & 1197 & 1275 & 1298 & 1335 & 1514 \\
\hline
\end{tabular}

MINIMUN TENSION (KN)

\begin{tabular}{llllllll}
\hline MOORING LINE & \multicolumn{6}{l}{ SEA STATES } \\
\cline { 2 - 8 } & 1 & 2 & 3 & 4 & 5 & 6 & 7 \\
\hline M1 & 1080 & 1130 & 1106 & 1142 & 1152 & 1197 & 1298 \\
M2 & 2835 & 3258 & 3002 & 3472 & 2902 & 3426 & 3331 \\
M3 & 1066 & 1117 & 1090 & 1132 & 1138 & 1179 & 1256 \\
\hline
\end{tabular}

TENSION DIFFERENCE (\%)

MOORING LINE SEA STATES

\begin{tabular}{llllllll} 
& 1 & 2 & 3 & 4 & 5 & 6 & 7 \\
\cline { 2 - 8 } M1 & 6 & 12 & 8 & 13 & 12 & 17 & 28 \\
M2 & 31 & 33 & 26 & 25 & 34 & 39 & 79 \\
M3 & 7 & 12 & 10 & 13 & 14 & 13 & 21 \\
\hline
\end{tabular}

sea states and mooring lines. In general, coefficients between 1.2-1.4 and 2.1-3.2 are obtained for the least and most loaded lines, respectively. Coefficients ranging from 1.5 to 4.1 are obtained for the most severe sea state.

\subsubsection{Influence of spectral shape on mooring loads}

This section analyses the mooring loads from perspective of spectral shape. The wave spectra considered are described in section 3.1.2, and the results are presented in this section. Load analysis is performed by comparing spectra and percentiles of tensions.

In Fig. 21, tension spectra are shown for the most loaded mooring line. The figure also shows a comparison among the three wave spectra considered (buoy data, JONSWAP $\gamma=3.3$, JONSWAP best $\gamma$ fit) for the four sea states. In general, the different approaches capture the main frequencies of tensions well. However, some discrepancies in the distribution of frequency energy are obtained. Sea states 1 and 2 can be considered swell sea states. For this reason, similar results in terms of spectral energy for each frequency are obtained between the buoy data and the JONSWAP formulation. However, the main frequency according to the buoy data shows a discrepancy with respect to the JONSWAP spectra in sea state 2 . This difference can be explained by the fact that the spectrum measured presents a second peak with an appreciable amount of energy at that frequency, as shown in Fig. 12. The spectra of sea states 3 and 4 are generated by local wind characterised by a lower amount of energy but with considerable frequency dispersion. Because the JONSWAP formulation considers a dominant frequency, it is expected to yield higher discrepancies in terms of frequency energy in these sea states. Nevertheless, similar results for the load spectrum are provided by the different spectra in sea state 3, generating significant differences in the distribution of energy in sea state 4.

After the frequency domain analysis, a statistical analysis of the mooring load response is carried out. First, a GEV distribution function is used to fit the tension series to be able to more accurately compare the implications of each approach. Fig. 22 compares the different mooring load distribution functions among the different approaches. A suitable adjustment is obtained through the GEV distribution with correlation coefficients in the region of 0.99 for each approach and sea state considered according to the QQ plot shown in Fig. 22. In general, 

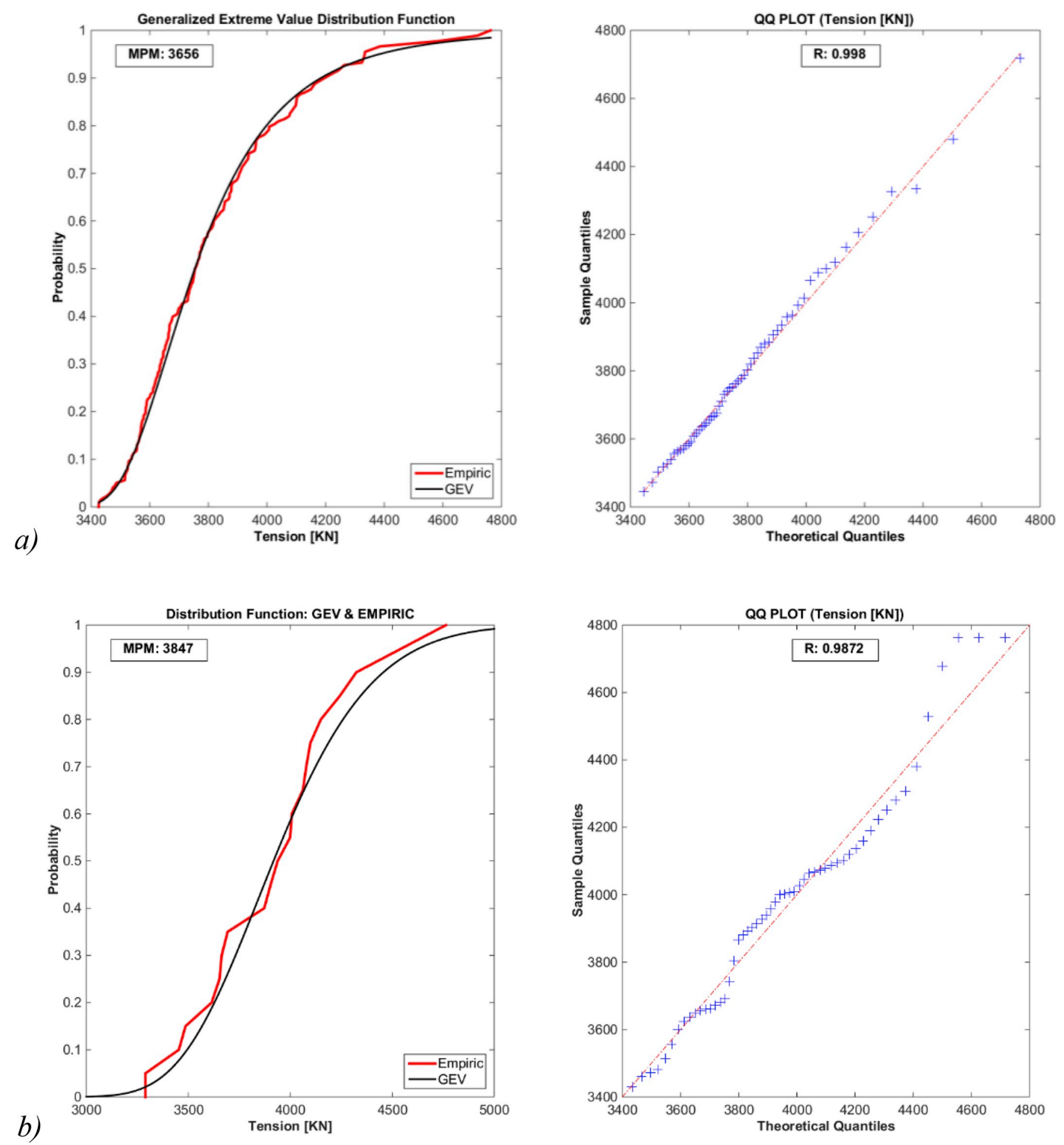

Fig. 20. Fit and QQ plot: case 6. a) Peak load method b) Maximum local load method.

buoy data overestimate the seaward line tension and underestimate the leeward line tension as opposed to the JONSWAP approaches. The discrepancy of these results suggests differences in the coupling to the platform response. Fig. 23 presents the surge offset for each state considered. All buoy sea states generate higher offset than JONSWAP approaches. Similar responses are obtained for the different JONSWAP spectrum definitions. These results show the importance of considering real spectra instead of theoretical spectra.

Finally, Fig. 24 shows the percentile differences (\%) between the JONSWAP approaches and the buoy data for all moorings and sea states. The percentiles used are 0.5, 0.9, 0.95 and 0.99. Positive values mean that predicted loads by JONSWAP spectra are higher than predicted loads by buoy data and vice versa. In general, loads obtained by the JONSWAP spectrum are overestimated for mooring lines M1 and M3 and underestimated for M2 with respect to the buoy data. Overestimated differences of less than $2 \%$ are observed in the least loaded mooring lines (M1 and M3) for JONSWAP with gamma 3.3, and differences of less than $4 \%$ are observed for the best JONSWAP fit in sea states 1 and 2 . The most loaded mooring line shows underestimated differences of less than $2 \%$ and $4 \%$ for JONSWAP with gamma 3.3 and 
Table 9

MPM of tensions for different criteria, sea states and mooring lines.

\begin{tabular}{llllllll}
\hline M1-MPM [KN] & SEA STATES & & & & & \\
\hline CRITERIA & 1 & 2 & 3 & 4 & 5 & 6 & 7 \\
\hline PEAK LOADS & 1089 & 1143 & 1121 & 1161 & 1202 & 1225 & 1346 \\
MAXIMUM LOCAL LOAD & 1127 & 1187 & 1180 & 1209 & 1268 & 1256 & 1452 \\
\hline M2-MPM [KN] & SEA STATES & & & & & \\
\hline CRITERIA & 1 & 2 & 3 & 4 & 5 & 6 & 7 \\
\hline PEAK LOADS & 2906 & 3412 & 3113 & 3650 & 3003 & 3656 & 3649 \\
MAXIMUM LOCAL LOAD & 3090 & 3535 & 3258 & 3751 & 3252 & 3847 & 3925 \\
\hline M3-MPM [KN] & SEA STATES & & & & & \\
\hline CRITERIA & 1 & 2 & 3 & 4 & 5 & 6 & 7 \\
\hline PEAK LOADS & 1074 & 1130 & 1105 & 1147 & 1178 & 1212 & 1321 \\
MAXIMUM LOCAL LOAD & 1100 & 1166 & 1142 & 1200 & 1224 & 1296 & 1436 \\
\hline
\end{tabular}

Table 10

Safety factors for different sea states and mooring lines.

\begin{tabular}{llllllll}
\hline MOORING LINE & \multicolumn{7}{l}{ SEA STATES } \\
\cline { 2 - 8 } & 1 & 2 & 3 & 4 & 5 & 6 & 7 \\
\hline M1 & 1.2 & 1.3 & 1.3 & 1.3 & 1.3 & 1.4 & 1.6 \\
M2 & 2.1 & 2.7 & 2.2 & 2.7 & 2.5 & 3.2 & 4.1 \\
M3 & 1.2 & 1.3 & 1.3 & 1.3 & 1.4 & 1.4 & 1.5 \\
\hline
\end{tabular}

JONSWAP with the best gamma fit, respectively. However, differences of approximately $12 \%$ are obtained in the 0.99 percentile in sea state 2 for the two JONSWAP approaches. Overestimated differences of less than $1 \%$ are observed between the JONSWAP approaches and the buoy data for the least loaded mooring lines in sea states 3 and 4, whereas those for the most loaded mooring are less than $4 \%$.

The results show that similar patterns are obtained for the different JONSWAP approaches with differences between them of less than $3 \%$ in the prediction of loads. The assumption of a theoretical spectrum instead of a real spectrum can generate uncertainties of up to $12 \%$ according to the sea states considered in this work.

\section{Conclusions}

To survive ultimate limit states, a mooring system must be designed to accurately estimate extreme line loads. An in-house numerical model, calibrated by tank testing, is used to estimate loads in a catenary mooring system. The estimated loads are sensitive to model setting, quasi-static or dynamic, and input wave characteristic, wave groupiness or spectra. In this article, extreme loads are analysed with various model settings, and safety factors on the mooring lines are recommended by taking into account different working regimes of the wind turbine. The aforementioned parameters are analysed on a FOWT located in the North of Spain.

The influence of the mooring numerical model is investigated in the analysis of peak loads. Dynamic models are more accurate than quasistatic models in the evaluation of extreme loads. Slight differences are found between the two models for mean loads of approximately $5 \%$ reaching $70 \%$ with respect to the maximum load parameters.

I-FORM is used to select the long-term data of the sea states. Different sea states are selected by considering the control used in the turbine and the characteristics of the waves. The effect of wave time
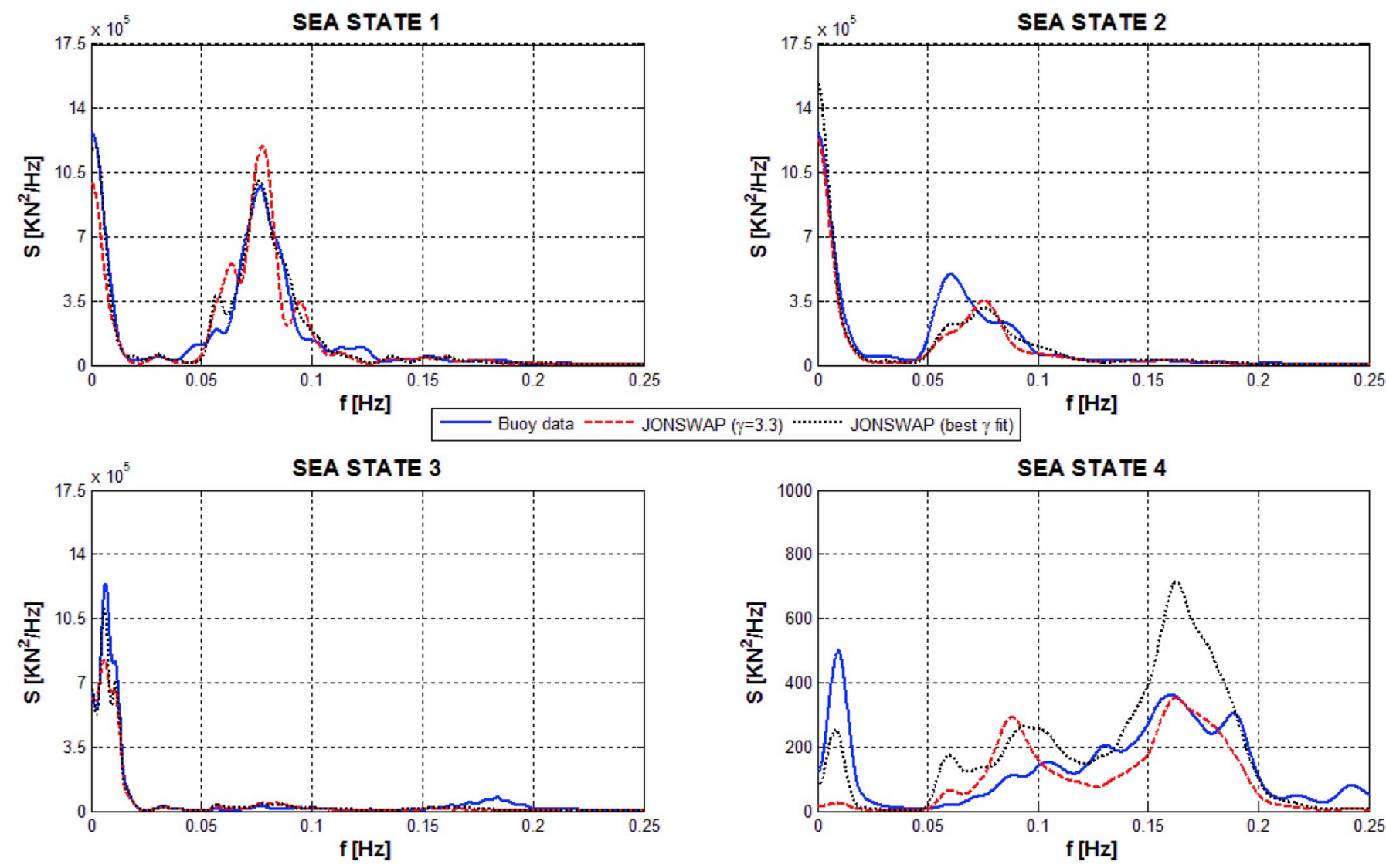

Fig. 21. Comparison of tensions spectra for all sea states: mooring line 2 . 

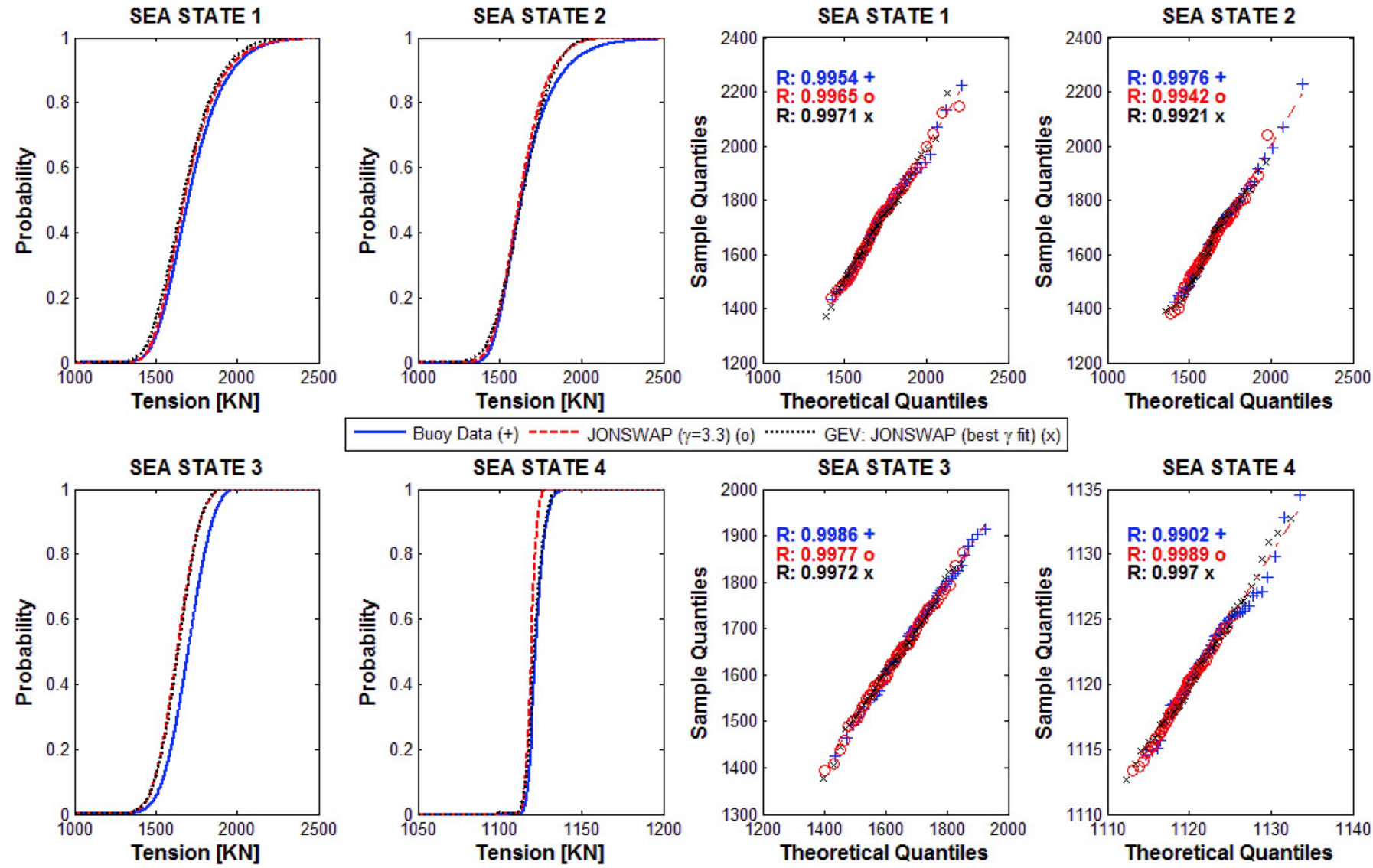

Fig. 22. Comparison of tension distribution function and QQ plot for all sea states: mooring line 2.

history for each sea state is analysed by proposing several cases with different distribution of wave groupiness. The results of simulations show significant load variability. For this reason, two extreme load studies are performed: one considering all peak loads and another considering only the maximum local load. The most probable maximum (MPM) is provided for each methodology as the design load proposed by the standards.
The influence of the real spectra in contrast to that of the theoretical spectra is analysed in this study. In general, the assumption of JONSWAP spectra implied an error below $12 \%$ in the evaluation of loads relative to that implied by real spectra.

To summarise, a methodology for evaluating the effect of different parameters related to metocean conditions on a mooring system is presented. This approach combines aerodynamic, hydrodynamic and

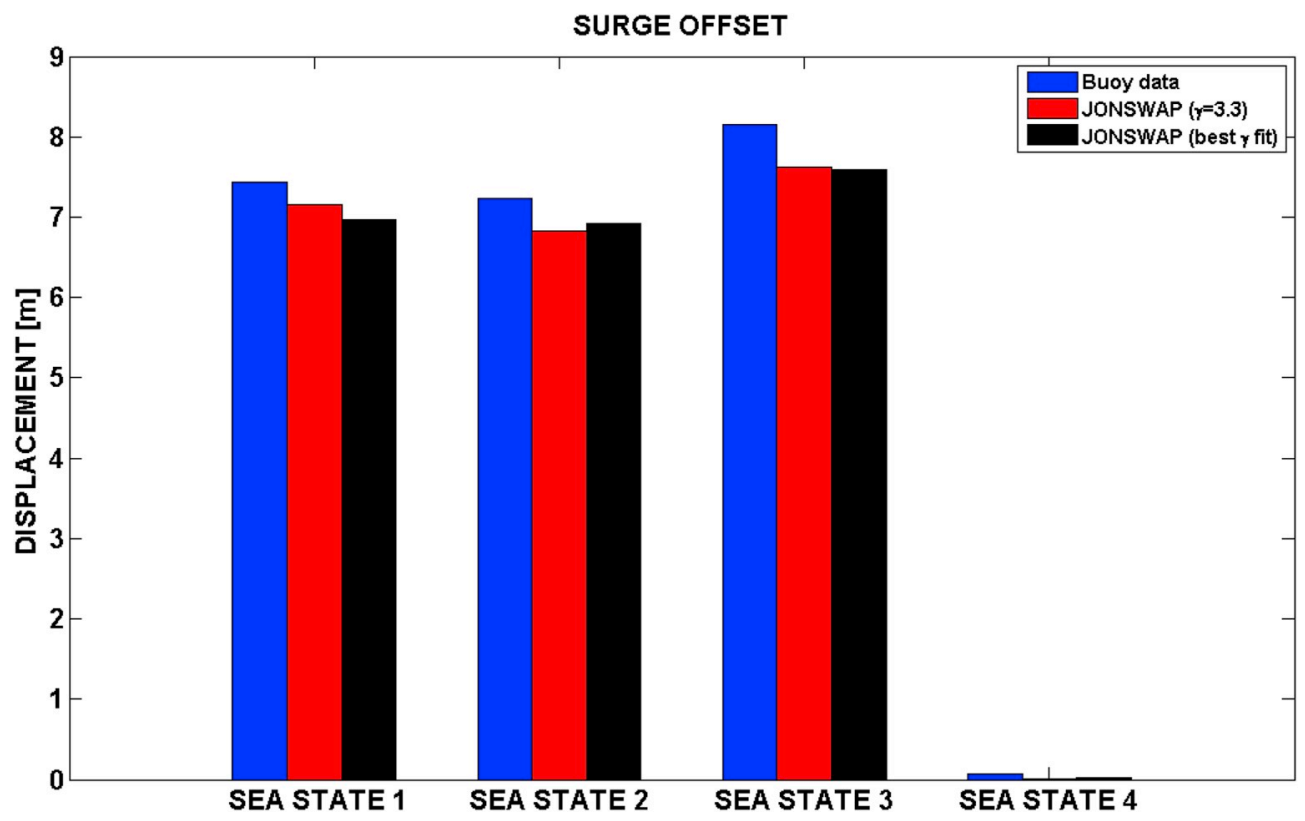

Fig. 23. Surge offset for each sea state and approaches. 

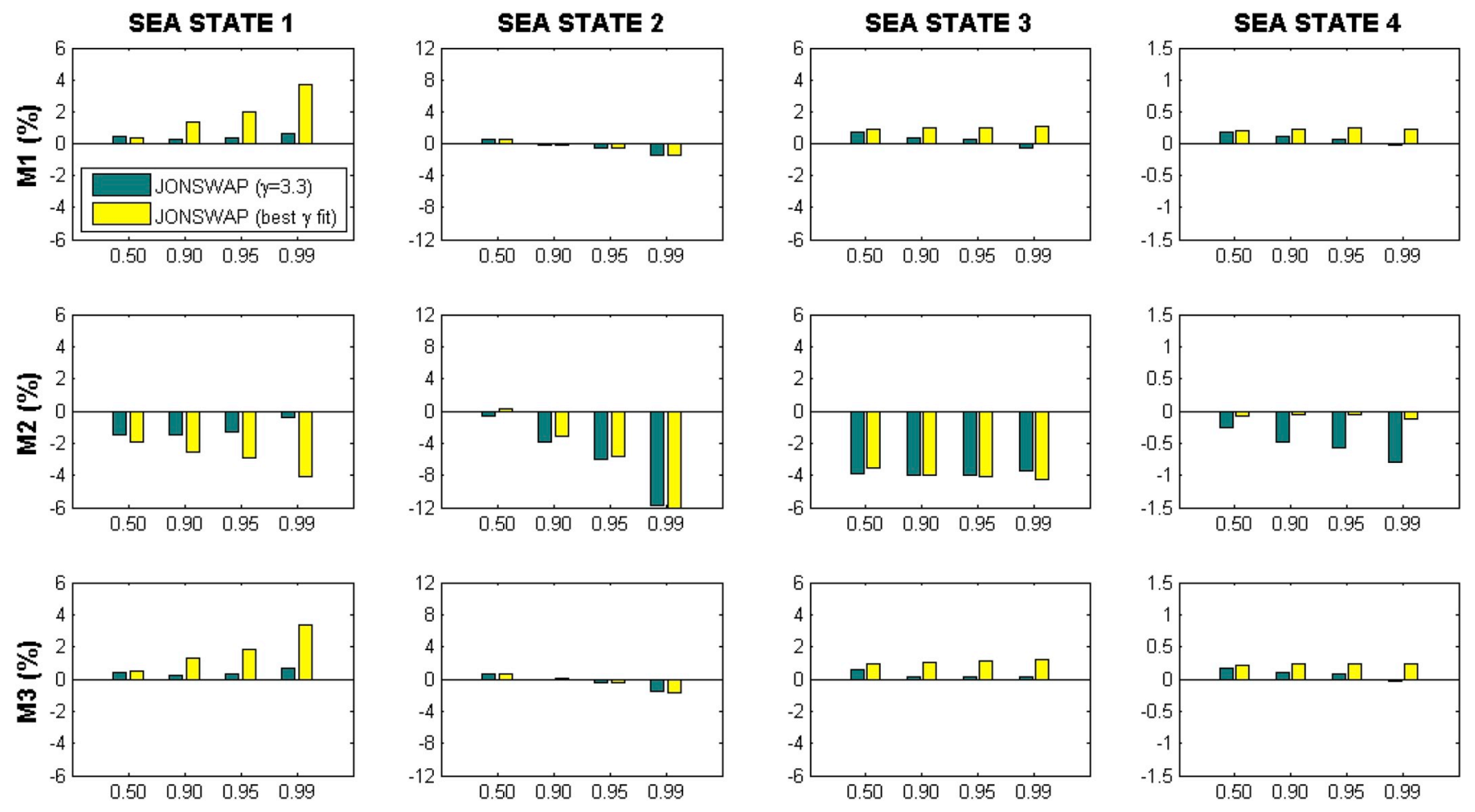

Fig. 24. Percentile differences (\%) between JONSWAP approaches and buoy for all mooring lines and sea states.

mooring models with statistical methods for the selection of sea states and the evaluation of loads. The dynamic analysis achieves better approximations in the evaluation of extreme loads than other methods, adopting statistical techniques in the design of extreme loads.

\section{Acknowledgements}

The authors acknowledge the financial support from the Spanish Ministry of Economy, Industry and Competitiveness for PhD candidate Carlos Barrera Sánchez through its National Programme for Mobility (EEBB-I-17-12083) and the University of Exeter as the receiving research centre. The authors also acknowledge Zunibal, who provided the ANTEIA buoy data, BiMEP, who provided the WAVESCAN buoy data, and the OC5 Project, which performed laboratory tests to calibrate and validate the numerical model. This work is part of two research projects: i) VAPEO - Influencia de la VAriabilidad climática del océano sobre la Producción de Energía de las Olas (grant agreement no: ENE2013-48716-R within National Programme for Research Aimed at the Challenges of Society, call 2013) and ii) ACOPLE - Análisis del COmportamiento dinámico de PLataformas Eólicas flotantes para la optimización del diseño de aguas profundas (grant agreement no: ENE2017-89716-R within the National Programme for Research, Development and Innovation Aimed at the Challenges of Society, call 2017). In addition, the $\mathrm{PhD}$ candidate is grateful to the aforementioned ministry for his research training scholarship (grant agreement no: BES2014-070381).

\section{References}

Aamo, O.M., Fossen, T.I., 2000. Finite element modelling of moored vessels. Math. Comput. Model. Dyn. Syst. 53, 415-422.

ANSYS AQWA, 2013. Version 15.0. ANSYS, Inc., Canonsburg, PA, USA November.

Armesto, J.A., Sarmiento, J., Ayllón, V., Iturrioz, A., Jurado, A., Guanche, R., Losada, I.J.,

2016. Numerical and experimental study of a multi-use platform. OMAE2016-54427.

In: Proceedings of the ASME 2016 35th International Conference on Ocean, Offshore and Arctic Engineering OMAE. Busan, South Korea.

Armesto, J.A., Ayllón, V., Barrera, C., Laguillo, C., Guanche, R., 2017. On the importance of restoring term approximations for large pitching floating devices. Int. J. Mar. Energy 19 (September), 164-176. https://doi.org/10.1016/j.ijome.2017.07.007.

Azcona, J., Munduate, X., González, L., Nygaard, T.A., 2017a. Experimental validation of a dynamic mooring lines code with tension and motion measurements of a submerged chain. Ocean Eng. 129, 415-427. https://doi.org/10.1016/j.oceaneng.2016.10.051.

Azcona, J., Palacio, D., Munduate, X., González, L., Nygaard, T.A., 2017b. Impact of mooring lines dynamics on the fatigue and ultimate loads of three offshore floating wind turbines computed with IEC 61400-3 guideline. Wind Energy 20, 797-813. https://doi.org/10.1002/we.2064.

Barrera, C., Guanche, R., Losada, I.J., Armesto, J.A., Arjona, S., Salas, J.F., Blanco, D., Álvarez, A., 2017. Experimental Modelling of Mooring Lines for Marine Energy Systems. In: III Marine Energy Week, Bilbao 27-31 March.

Barrera, C., Guanche, R., Losada, I.J., 2019. Experimental modelling of mooring systems for floating marine energy concepts. Mar. Struct. 63, 153-180. https://doi.org/10. 1016/j.marstruc.2018.08.003.

Camus, P., Mendez, F., Medina, R., Cofiño, A., 2011. Analysis of clustering and selection algorithms for the study of multivariate wave climate. Coast Eng. 58, 453-462. https://doi.org/10.1016/j.coastaleng.2011.02.003.

Cummins, W.E., 1962. The impulse response function and ship motions. Schiff-stechnik 9 , 101-109.

De los Dolores, D., Meseguer, A., Armesto, J.A., Martini, M., Guanche, R., 2017. Aerodynamic wind turbine model for floating offshore wind platform. In: III Marine Energy Week, Bilbao 27-31 March.

Del Jesus, F., Guanche, R., Losada, I.J., 2015. New proposal for extreme data management for offshore wind applications. In: The Proceedings of the European Wind Energy Association (EWEA), Paris, France.

DNV-OS-J101, May 2014. Design of Offshore Wind Turbine Structure.

DNV-RP-C205, April 2014. Environmental Conditions and Environmental Loads.

DNVGL-OS-E301, July 2015. Position Mooring. Offshore Standard.

Duarte, T., Sarmento, A., Jonkman, J., 2014. Effects of second-order hydrodynamic forces on floating offshore wind turbines. In: AIAA SciTech 2014 National Harbour, Maryland January 13-17.

Gueydon, S., Duarte, T., Jonkman, J., Bayati, I., Sarmento, A., 2014. Comparison of Second Order Loads on a Semisubmersible Floating Wind Turbine. In: 33rd International Conference on Ocean, Offshore and Arctic Engineering, San Francisco, California June 8 - 13.

Hall, M., Goupee, A., 2015. Validation of a lumped-mass mooring line model with DeepCwind semisubmersible model test data. Ocean Eng. 104, 590-603. https://doi. org/10.1016/j.oceaneng.2015.05.035.

Harnois, V., Thies, P.R., Johanning, L., 2016. On peak mooring loads and the influence of environmental conditions for marine energy converters. MPDI J. Mar. Sci. Eng. 4, 29. https://doi.org/10.3390/jmse4020029.

Harris, R.E., Johanning, L., Wolfram, J., 2004. Mooring systems for wave energy converters: a review of design issues and choices. In: Proceedings of the 3rd International Conference on Marine Renewable Energy (MAREC), Blyth, UK, 7-9 July.

Haukanes, A.L., Ronold, K.O., Argyriadis, K., 2017. Revision of DNV-GL design standard 
for floating wind turbine structures. OMAE2017-62313. In: Proceedings of the ASME 2017 36th International Conference on Ocean, Offshore and Arctic Engineering OMAE 2017, June 25-30, (Trondheim, Norway).

Haver, S., Winterstein, S.R. Environmental Contour Lines: a Method for Estimating Long Term Extremes by a Short Term Analysis. The Society of Naval Architecs and Marine Engineers. SMTC-067-2008.

Hsu, W.-T., Thiagarajan, K.P., Manuel, L., 2017. Extreme mooring tensions due to snap loads on a floating offshore wind turbine system. Mar. Struct. 55, 182-199. https:// doi.org/10.1016/j.marstruc.2017.05.005.

IEC 61400-3 Wind Turbines - Part 3: Design Requirements for Offshore Wind Turbines.

Iturrioz, A., del Jesus, F., Guanche, R., Acevedo, A., Chiri, H., Abascal, A.J., García, A., Espejo, A., Losada, I.J., Marina, D., Torre-Enciso, Y., 2017. Metocean characterization of BiMEP for WEC design. In: Proceedings of 12th European, Wave and Tidal Energy Conference. Cork, Ireland.

Jonkman, J.M., Buhl Jr., M.L., 2007. Development and Verification of a Fully Coupled Simulator for Offshore Wind Turbines. $45^{\text {th }}$ AIAA Aerospace Sciences Meeting and Exhibit. Wind Energy Symposium Reno, Nevada.

Jonkman, B.J., Kilcher, L., September 2012. Technical Report: TurbSim User's Guide: Version 1.06.00. National Renewable Energy Laboratory.

Jonkman, J., Butterfield, S., Musial, W., Scott, G., February 2009. Technical Report: Definition of a 5-MW Reference Wind Turbine for Offshore System Development. National Renewable Energy Laboratory NREL/TP-500-38060.

Lara, J.L., Garcia, N., Losada, I.J., 2006. RANS modelling applied to random wave interaction with submerged permeable structures. Coast Eng. 53 (5-6), 395-417 (ELSEVIER).

Lindahl, J., 1985. "Modellförsök med en förankringskabel". Report Series A:12. Department of Hydraulics, Chalmers University of Technology.

Madsen, H.O., Krenk, S., Lind, N.C., 1986. Methods of Structural Reliability. PrenticeHall, Englewood Cliffs, New Jersey.

Martini, M., Guanche, R., Armesto, J.A., Losada, I.J., Vidal, C., 2015. Met-ocean conditions influence on floating offshore wind farms power production. Wind Energy 19 (3), 399-420. https://doi.org/10.1002/we.1840.

Menendez, M., García-Diez, M., Fita, L., Fernández, J., Méndez, F.J., Gutiérrez, J.M., 2014. High-resolution sea wind hindcasts over the mediterranean area. Clim. Dynam. 42 (7-8), 1857-1872. http://link.springer.com/10.1007/s00382-013-1912-8.

Metocean analysis of BiMEP for offshore design. In: Produced by IHCantabria and Bimep in the Framework of TRL + Project, . www.trlplus.com.

Pinkster, J.A., 1980. Low Frequency Second Order Wave Exciting Forces on Floating Structures. NSMB Publication No. 650, Wageningen, Netherlands.

Reguero, B.G., Menéndez, M., Méndez, F.J., Mínguez, R., Losada, I.J., 2012. A Global Ocean Wave (GOW) calibrated reanalysis from 1948 onwards. Coast Eng. 65, 38-55. https://doi.org/10.1016/j.coastaleng.2012.03.003.

Ris, R.C., Cecchi, E., Holthuijsen, L.H., Booij, H., 1999. Effects on Low-frequency Waves on Wave Growth in Swan: Validation and Verification of an Extended Whitecapping Formulation, vol. 3529 WL Delft Hydraulics report H.

Robertson, A., Jonkman, J., Vorpahl, F., Popko, W., Qvist, J., Frøyd, L., Chen, X., Azcona J., Uzunoglu, E., Guedes Soares, C., Luan, C., Yutong, H., Pengcheng, F., Yde, A., Larsen, T., Nichols, J., Buils, R., Lei, L., Anders Nygard, T., Manolas, D., Heege, A., Ringdalen Vatne, S., Ormberg, H., Duarte, T., Godreau, C., Fabricius Hansen, H., Wedel Nielsen, A., Riber, H., Le Cunff, C., Abele, R., Beyer, F., Yamaguchi, A., Jin Jung, K., Shin, H., Shi, W., Park, H., Alves, M., Guérinel, M., 2014. Offshore code comparison collaboration continuation within IEA wind task 30: phase ii results regarding a floating semisubmersible wind system. In: Proceedings of the 33rd International Conference on Ocean. Offshore and Arctic Engineering, San Francisco, California, USA 2014

Robertson, A., Wendt, F., Jonkman, J., Popko, W., Dagher, H., Gueydon, S., Qvist, J., Vittori, F., Azcona, J., Uzunoglu, E., Guedes Soares, C., Harries, R., Yde, A., Galinos, C., Hermans, K., Bernardus de Vaal, J., Bozonnet, P., Bouy, L., Bayati, I., Bergua, R. Galvan, J., Mendikoa, I., Barrera, C., Shin, H., Oh, S., Molins, C., Debruyne, Y., 2017. OC5 Project Phase II: validation of global loads of the deepCwind floating semisubmersible wind turbine. Energy Procedia 137, 38-57. https://doi.org/10.1016/j. egypro.2017.10.333.

Robertson, A., Jonkman, J., Wendt, F., Goupee, A., Dagher, H. Technical report: definition of the OC5 DeepCwind semisubmersible floating system. Nat. Renew. Energy Lab. Univ. Maine.

Saha, S., Moorthi, S., Pan, H.-L., Wu, X., Wang, J., Nadiga, S., Tripp, P., Kistler, R., Woollen, J., Behringer, D., Liu, H., Stokes, D., Grumbine, D., Gayno, G., Wang, J., Hou, Y.-T., Chuang, H-y., Juang, H.-M.H., Sela, J., Iredell, M., Treadon, R., Kleist, D. Van Delst, P., Keyser, D., Derber, J., Ek, M., Meng, J., Wei, H., Yang, R., Lord, S., van den Dool, H., Kumar, A., Wang, W., Long, C., Chelliah, M., Xue, Y., Huang, B., Schemm, J.-K., Ebisuzaki, W., Lin, R., Xie, P., Chen, M., Zhou, S., Higgins, W., Zou, C.Z., Liu, Q., Chen, Y., Han, Y., Cucurull, L., Reynolds, R.W., Rutledge, G., Goldberg, M., 2010. The NCEP climate Forecast system reanalysis. Bull. Am. Meteorol. Soc. 91 (8), 1015-1057. http://journals.amersoc.org/doi/abs/10.1175/2010BAMS3001.1.

Simos, A.N., Ruggeri, F., Watai, R.A., Souto, A., Lopez, C., 2018. Slow-drift of a floating wind turbine: an assessment of frequency-domain methods based on model tests. Renew. Energy 116, 133-154. Part A, February. https://doi.org/10.1016/j.renene. 2017.09.059.

Skamarock, W.C., Klemp, J.B., Dudhia, J., Gill, D.O., Baker, D.M., Duda, M.G., Huang, X. Y., Wang, W., Powers, J.G., 2008. A Description of the Advanced Research WRF Version 3. NCAR/TN-475 + STR. National Center for Atmospheric Research, Boulder, CO, USA. 